\title{
Re-Excavation of Dabangay, a Mid-Holocene Settlement Site on Mabuyag in Western Torres Strait
}

\author{
Duncan Wright ${ }^{1}$, Peter Hiscock ${ }^{2}$ and Ken Aplin $^{3}$
}

1 School of Archaeology and Anthropology, Australian National University, Canberra ACT 0200 Duncan.Wright@anu.edu.au

2 Department of Archaeology, University of Sydney, NSW 2006, Australia peter.hiscock@sydney.edu.au

3 Division of Mammals, National Museum of Natural History, Smithsonian Institution, Washington D.C. 20013-7012, USA aplink@si.edu

\begin{abstract}
The discovery and initial excavation of Dabangay in 2006 established a 7200 year chronology for human settlement on Mabuyag (Mabuiag) in western Torres Strait. This was one of only two Torres Strait sites to pre-date 4000 years ago, providing a rare opportunity to study human activities spanning the mid-to-late Holocene. Remarkable organic preservation and a large mid-Holocene stone artefact assemblage provided insights into long-term continuity and change in lithic technologies and economic strategies; however, results remained preliminary owing to uncertainties about site disturbance. This paper presents results from a second field season of excavations at Dabangay. We suggest chronological association between emerging lithic technologies and altered subsistence practices. Large marine vertebrate bone (present in small quantities from initial settlement), increased after 4200 years ago coincident with increased preference for production of quartz bipolar flakes. A further development after 1800-1600 years ago involved a substantial increase in large and small marine vertebrates and a further increase in the ratio of quartz to igneous lithics.
\end{abstract}

\section{Introduction}

A long-standing interest for researchers working in Torres Strait has been the chronology and nature of human settlement during the mid-Holocene (cf. Barham et al. 2004:53; David et al. 2004; Moore 1979; Rowland 1985). Only four sites (Badu 15 and Badu 19 on Badu; Dabangay on Mabuyag and Mask Cave on Pulu) pre-date 2500 years ago, and until now the sequence from Badu 15 was the only one with a record beyond 4000 years ago (Crouch et al. 2007; David et al. 2004; McNiven et al. 2006; Wright 2011) (Figure 1). The paucity of undisturbed midHolocene sites, coupled with absence of pre-4000 year old faunal remains or sizable lithic assemblages has made it difficult to assess long-term continuity and change in Torres Strait economies. In this paper we present results from the re-excavation of Dabangay, a site that now provides an intact, 7000 year old cultural record.

The significance of these findings can be considered in light of previously published interpretations from midHolocene sites in western Torres Strait. The Badu 15 cave provides the earliest direct evidence for human occupation in Torres Strait, suggesting three phases of activity: permanent occupation (between 8000-6000 cal $\mathrm{BP})$, fleeting presence (6000-3500 cal BP) and recurrent if not permanent occupation (after 3500 cal BP; David et al. 2004:75). Dabangay, an open site on Mabuyag, experienced sustained settlement between 7239-4901 cal $\mathrm{BP}$, suggesting islanders survived (or quickly repopulated) western Torres Strait after the isthmus-toisland transition (Wright 2011; Wright and Jacobsen in press). The interface between mid-to-late Holocene layers was obscured by significant termite disturbance.

Low intensity occupation by marine specialists was recorded on two small islets, Berberass and Pulu between 3800-2400 cal BP (Crouch et al. 2007; McNiven et al. 2006). Mask Cave (Pulu) and Badu 19 (Berberass) experienced 'a dramatic burst' of activity after 2600-2500 cal BP, interpreted as evidence for a migration of 'Papuan maritime, horticultural and pottery-making peoples to the eastern and western islands' (McNiven et al. 2006:49; see also Crouch et al. 2007:61-62). At Woam village on Saibai Island (northwest Torres Strait) a bone and shell midden was radiocarbon dated to $1080 \pm 60$ BP (Beta6934) or (based on one 'chronologically anomalous' determination) 2540 \pm 60 BP (Beta-6885) (Barham 1999:79). Due to uncertainties surrounding the chronology of this site we do not include it in our review.

In the following sections we focus on observed transitions in lithic technology and subsistence on Torres Strait Islands, before reporting results from recent excavations at Dabangay.

\section{Is there Evidence for Changes in Lithic Technology during the Mid-to-Late Holocene?}

Barham et al. (2004:53) observed that '[a]rchaeological data offers little to supplement ethnographic accounts of lithic trade movements ... Almost all evidence for lithic use and manufacture is non-stratigraphic'. A detailed record was recently provided for a late Holocene stratified assemblage at Dauan 4, in the northwestern islands (McNiven 2006), however long-term change in artefact technologies remains poorly understood.

At Badu 15, 'the only definite cultural materials' were lithics, with 17 definite and 11 likely stone artefacts excavated from layers pre-dating $6854 \mathrm{cal} \mathrm{BP}$ and a larger number (46 definite and 24 likely) excavated from layers post-dating 3317 cal BP (David et al. 2004:70-71). Detailed analysis of this lithic assemblage remains unpublished; however, David et al. (2004:71) observed consistency in size (small) and material ('quartz and volcanic rocks').

At Dabangay, the excavation of Square A yielded 314 quartz and 43 igneous artefacts from layers dated between 7239-4901 cal BP (XUs 34-48) (Wright 2011; Wright and Jacobsen in press). This may underestimate the midHolocene component as post-depositional mixing 


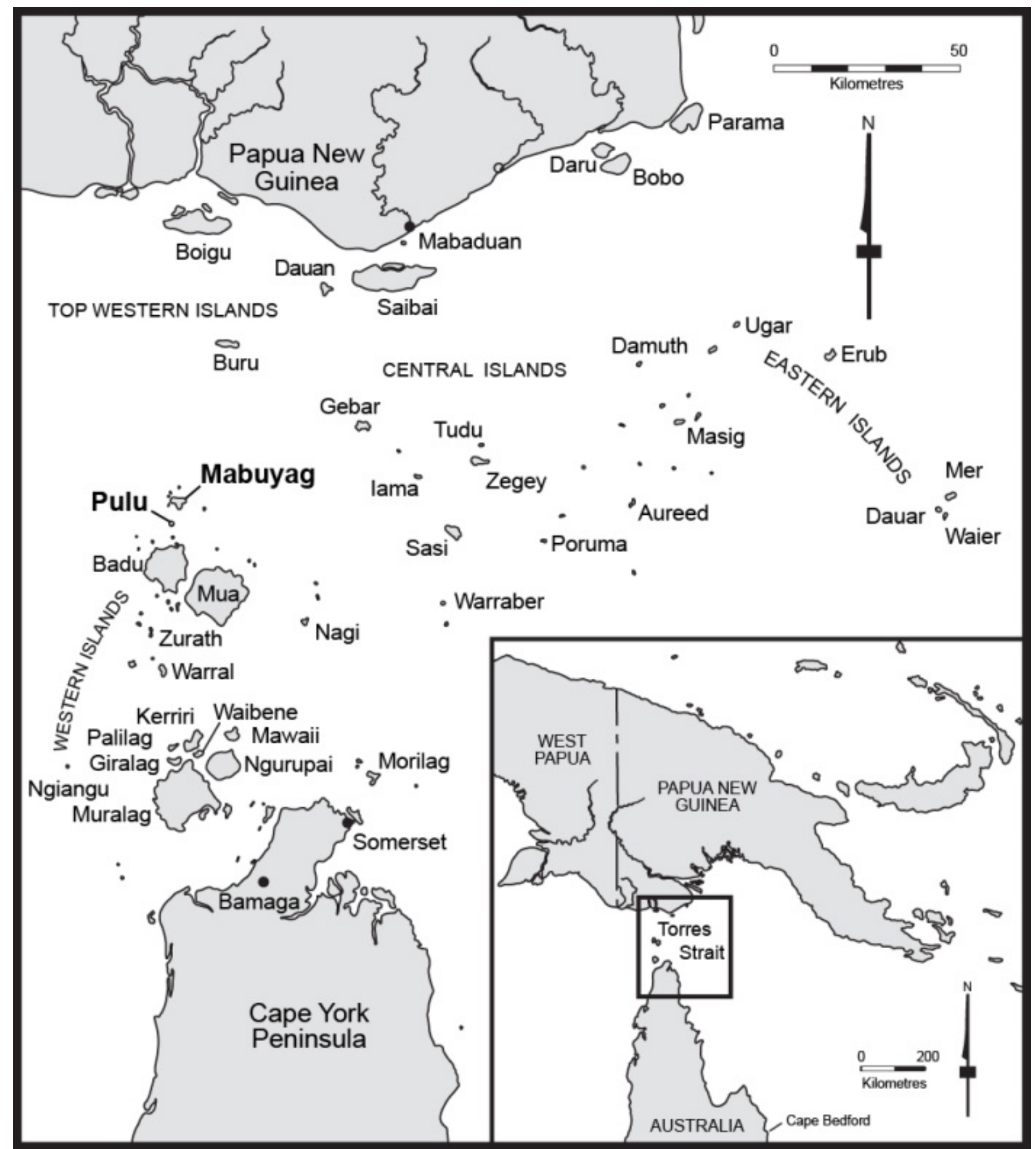

Figure 1. The location of Mabuyag (Mabuiag) in western Torres Strait. 
occurred at the interface between mid- and late Holocene layers (see Wright 2011 for details). Quartz flaked artefacts (average $=0.11 \mathrm{~g}$ ) were smaller than igneous artefacts (average $=5.3 \mathrm{~g}$ ). Fragments of ochre and a ground stone nodule were excavated in deposits dating to 6468-6033 cal BP (Wright 2011). Layers dated to the past 300 years produced a larger assemblage comprising 13,964 quartz and 1353 igneous flaked artefacts. A reduction in average weight of igneous lithics was observed (from 5.3g to 1.4g) and a slight increase in average weight of quartz artefacts (from $0.11 \mathrm{~g}$ to $0.15 \mathrm{~g}$ ) (Wright 2011). It is acknowledged that average weight, employed in the initial report as an expression of abundance is not always a useful measure because it is affected by sampling complexities including extent of reduction and natural breakage. The bulk of excavated ochre (including ground fragments) came from these upper layers.

At Mask Cave, lithics $(\mathrm{n}=842)$ were consistently small (average $=0.6 \mathrm{~g})$, manufactured from quartz $(77 \%)$, rhylote ignimbrite $(18 \%)$, granite $(3 \%)$, microgranite and felsic dikes (1\%) and volcanic (1\%) stone (McNiven et al. 2006:62). McNiven et al. (2006:60) recorded a 'major division in cultural items ... between lower levels dated to 2900-3800 years ago and upper levels dated within the last 2600 years'. While rhyolitic ignimbrite and quartz were in predominant use throughout, microgranite and felsic dike rocks (i.e. markers of isolated source outcrops) were more common during the later period (McNiven et al. 2006:63). McNiven et al. (2006:63) were uncertain whether this indicated an initial 'lack of familiarity of rock outcrops' or 'new functional requirements of stone tools and the need for finer-grained raw materials'. Large quantities of lithics were recovered from contexts postdating 1700 years ago, with quartz bipolar flakes the dominant form (McNiven et al. 2006:63).

At Badu 19, little vertical change was observed in lithic size, material or manufacture (Crouch et al. 2007). Flaked artefacts were consistently small (average $=0.3 \mathrm{~g}$ ), with quartz (88\%) dominant, and a small igneous component (12\%) (Crouch et al. 2007:58). Most quartz lithics were made from 'crystal-facet' and 'other', suggesting targeted collection from 'terrestrial exposures' and 'veins within granite outcrops' (Crouch et al. 2007:58). Quartz artefacts 'exhibit evidence of bipolar (anvil) reduction', not observed for the six igneous artefacts (Crouch et al. 2007:58). The lack of cortex on igneous cores suggested original reduction away from Berberass. Consistent with Mask Cave, the Badu 19 assemblage suggested an increase in lithic discard rates after 2600-2500 cal BP.

At Dauan 4, little change was observed within the past 700 years, with the assemblage dominated by quartz bipolar micro-cores and flakes (McNiven 2006:6). Based on ethnographic analogy, McNiven (2006:6) suggested that 'bipolar quartz artefacts may have been used, at least in part, for social (cicatrices) and/or therapeutic (bloodletting) reasons'. Quartz may also have been used for renewing the edge of bamboo knives and for sawing once hafted onto a handle (McNiven 2006:6). The small size of flakes and the lack of correlation between distribution of artefacts and faunal remains suggested butchering was not the principal purpose for small quartz artefacts.
In summary, lithic analyses at a range of sites across the region reveal consistent use of locally available raw materials (e.g. igneous, volcanic, quartz) through the past 8000 years but with several changes in raw material selection and reduction technology. After 4000 years ago there is evidence for production of large numbers of small, quartz, bipolar flakes and cores (Crouch et al. 2007; McNiven et al. 2006) and potentially a reduction in size of igneous artefacts (Wright 2011). After 2600-2500 years ago, a marked increase in lithic discard rates and a shift towards fine-grained raw materials suggests a major alteration in western Torres Strait settlement and subsistence activities (Crouch et al. 2007; McNiven et al. 2006). Bipolar micro-cores may have become increasingly prominent after 1700 years ago (McNiven 2006; McNiven et al. 2006).

\section{Is there Evidence for Changes in Subsistence Practices during the Mid-to-Late Holocene?}

Present Torres Strait Islanders are maritime specialists, the sea 'pervading cosmologies, oral traditions, art, material culture, songs, dances, ceremonies, rituals, and subsistence' (Crouch et al. 2007:50; see also Barham 2000; Beckett 1972; Haddon 1904; McNiven and Feldman 2003). The development of these specialised 'Islander' economies is expected to have been at least partially dependent on geomorphologic and palaeoenvironmental shifts connected with sea-level change (see Barham and Chappell 2005; Lambeck and Chappell 2001; Rowe 2011 for details). Faunal remains within archaeological contexts provide direct insight into the antiquity of environmental changes and the socioeconomic responses of Islander communities (e.g. Barham 2000; Barham et al. 2004; Crouch et al. 2007; McNiven et al. 2006; Wright 2011).

Dabangay provides the earliest direct evidence for human subsistence activities in Torres Strait. Large (dugong and turtle) and small (fish) marine vertebrate bones were recovered in small quantities from deposits dating between 7239-4901 cal BP, with a fragment of large marine vertebrate bone (probably dugong) dated to 6480-6256 cal BP (Wright and Jacobsen in press). This suggested that human populations possessed skills and technologies appropriate for targeting both large and small marine vertebrates soon after marine transgression.

Only two sites (Badu 19 and Mask Cave) provide evidence for human subsistence practices between 40002500 years ago. At Mask Cave, fragments of large marine vertebrates (mainly turtle) and fish were excavated from layers post-dating 4000 years ago (McNiven et al. 2006). McNiven et al. (2006:62) suggested 'a marine subsistence focus on offshore (turtle and to a lesser extent dugong) and near-shore low tide reef pool (small fish) resources throughout the site history'. At Berberass layers dating between 4000-2600 years ago produced fauna derived from varied habitats (including sandy, rocky, and coralreef littoral) but dominated by a gastropod Nerita sp. and Emperor fishes (Lethrinidae) (Crouch et al. 2007:57).

After 2600 years ago the Badu 19 sequence shows 'a clear chronological difference between the range of fish caught', with sharks and rays (Elasmobranchii), puffers (Tetraodontidae) and wrasses (Labridae) replacing Emperors. Quantities of dugong and turtle bone increased 


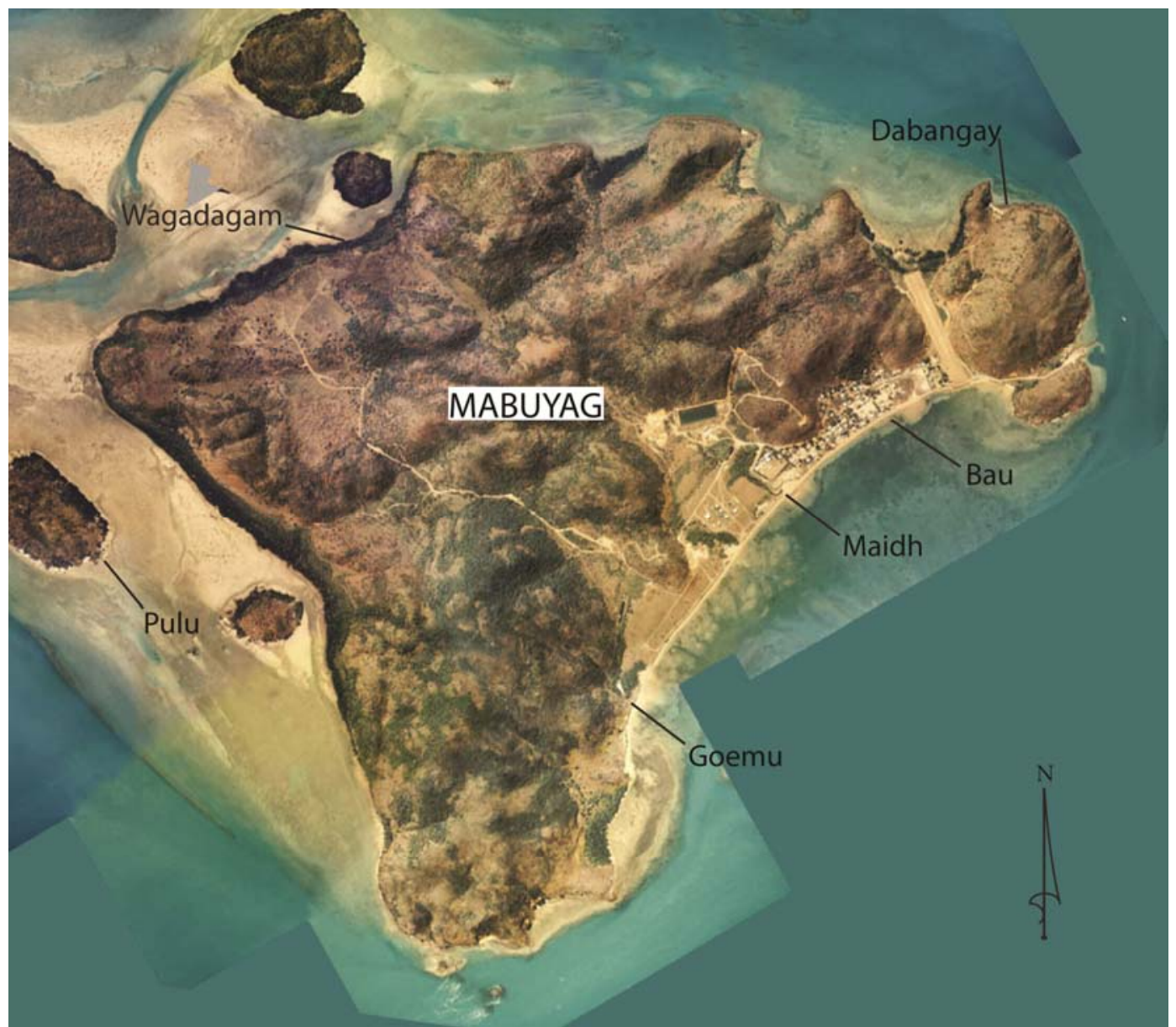

Figure 2. The location of Dabangay on Mabuyag in relation to ethnographically-significant 'villages' and islands. Prototype courtesy of Schlenker Mapping and Matt Coller. Aligned grid north.

while shellfish decreased suggesting to some researchers the development of 'advanced marine subsistence practices' with 'a greater emphasis on larger, marine animals’ (Crouch et al. 2007:60). At Mask Cave a larger quantity of faunal remains was observed after 2500 years ago, with crustaceans, shark, parrotfish (Scaridae) and puffers added to the diet (McNiven et al. 2006:59). Crouch et al. (2007:57) used the faunal evidence from these sites to infer 'long-term importance of inshore resources to Torres Strait Islanders'.

During the past 1400 years (and frequently after 600 800 years ago) there is a substantial increase in midden activity (including dugong, turtle bone and shellfish) in western Torres Strait sites, including Tigershark Rockshelter and the Kod on Pulu (McNiven et al. 2008, 2009); Goemu on Mabuyag (Ghaleb 1990; McNiven et al. in press); St Paul's Beach and Totolai on Mua (Ash and David 2008; Barham 2000); Kurturawniaiwak on Badu (David and Weisler 2006) and Dauan 4 in northwest Torres Strait (McNiven 2006). During this period the variety of targeted taxa increased including shark, rays, turtle, dugong as well as numerous fish and shellfish taxa (McNiven and Hitchcock 2004:110; McNiven et al. 2008:20). Arrangements of dugong bone and Syrinx aruanus shell become prominent within the past 500-400 years (David et al. 2005; McNiven and Feldman 2003). This is expected to mark widespread socio-political and ceremonial change and an increased focus on the sea (David et al. 2005; McNiven and Feldman 2003; McNiven and Hitchcock 2004).
In summary, the earliest faunal evidence at Dabangay between 7239-4901 cal BP indicates low intensity use of inshore (small fish) and offshore (dugong and turtle) resources during this period (Wright 2011). Dugong and turtle hunting and fishing may have escalated after 4000 years ago, with large marine vertebrate remains present in coastal sites on Pulu and Berberass (Crouch et al. 2007; McNiven et al. 2006). After 2600 years ago, there is an increase at Badu 19 and Mask Cave in both the quantity and variety of fish species caught, with a transition from littoral reef species (Emperors) to varied deep and shallow water species (Crouch et al. 2007). Badu 19 and Mask Cave provide divergent histories for shellfish exploitation within the past 2500 years (Crouch et al. 2007; McNiven et al. 2006). Midden quantities of marine vertebrate bone appear across multiple sites in western Torres Strait during the past 1000 years. In the subsequent sections we present results from recent re-excavation of Dabangay, concentrating on lithics and faunal remains to provide new insights into the regional economy.

\section{Dabangay}

Dabangay (previously known as Dabangai) is an ethnographically significant village situated on the northeast coast of Mabuyag (Figure 2). In the late nineteenth century, Dabangay was used as a residence for missionary teachers (Murray 1873) and was headquarters of the dugong (dhangal) clan who lived 'in huts, pitched under the shelter of some enormous banyan trees' (Moresby 1876:131; also McFarlane 1874). 


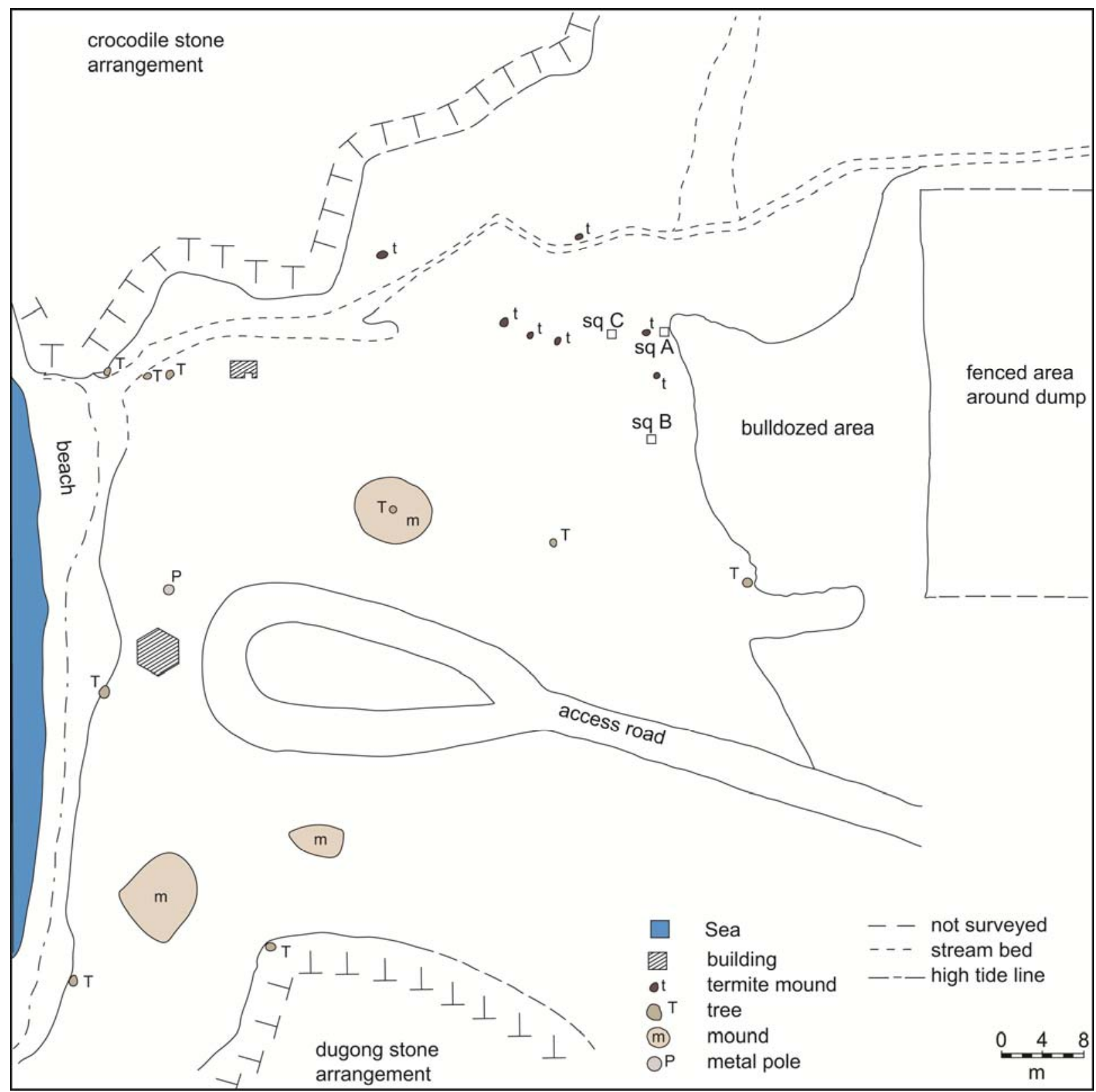

Figure 3. Map of the 2006 (Square A) and 2011 (Squares B and C) excavations at Dabangay.

In the 1980s, archaeological research identified abundant features including 30 stone-bone-shell mounds, five turret-like stone 'cairns' and one crocodile stone arrangement (Harris and Ghaleb 1987:27-28; Harris et al. 1985:48). The village was associated with a large number of mound-and-ditch fields along with 'rectangular units which may represent old occupation areas, or former fields’ (Harris and Ghaleb 1987:48; Harris et al. 1985:48). Harris and Ghaleb (1987:28) observed that 'parts of some of the field mounds and ditches appear to underlie the edges of some of the stone-bone-shell mounds, suggesting that they pre-date the latter'. A radiocarbon date of 674 \pm 35 BP (Wk-16365) (1508-1676 cal BP after correction) was obtained from marine shell at the base of a large dugong bone mound (McNiven and Bedingfield 2008:510). In September 2006, as part of the Western Torres Strait Cultural History Project (David and McNiven 2004) a single $1 \mathrm{~m}^{2}$ excavation (Square A) was conducted $55 \mathrm{~m}$ inland from, and $12 \mathrm{~m}$ above, the current high water mark in an area of level midden (Wright 2011) (Figure 3).
In November 2011, two $1 \mathrm{~m}^{2}$ excavations were completed to improve the settlement chronology for Dabangay and test the extent of mid-Holocene activity across the embayment. Square B was located $13.5 \mathrm{~m}$ north of Square A but was discontinued due to termite disturbance, time constraints and the poor preservation of cultural materials. Here, results are presented for both squares however we focus on the less disturbed Square C, located $5 \mathrm{~m}$ west of Square A and $18 \mathrm{~m}$ from the current high-tide line.

\section{Square C}

Square C was excavated to a depth of $197 \mathrm{~cm}$ below surface (BS) including $15 \mathrm{~cm}$ of culturally sterile, basal deposit. Excavation units (XUs) were guided by natural changes in stratigraphy and averaged $3.4 \mathrm{~cm}$ in depth, not including the preliminary sweep of top-soil (XU1). All sediment was wet-sieved through $2.1 \mathrm{~mm}$ mesh, with samples collected for sediment size and pollen analyses from excavation units and a column sample in the west wall (Figure 4). 


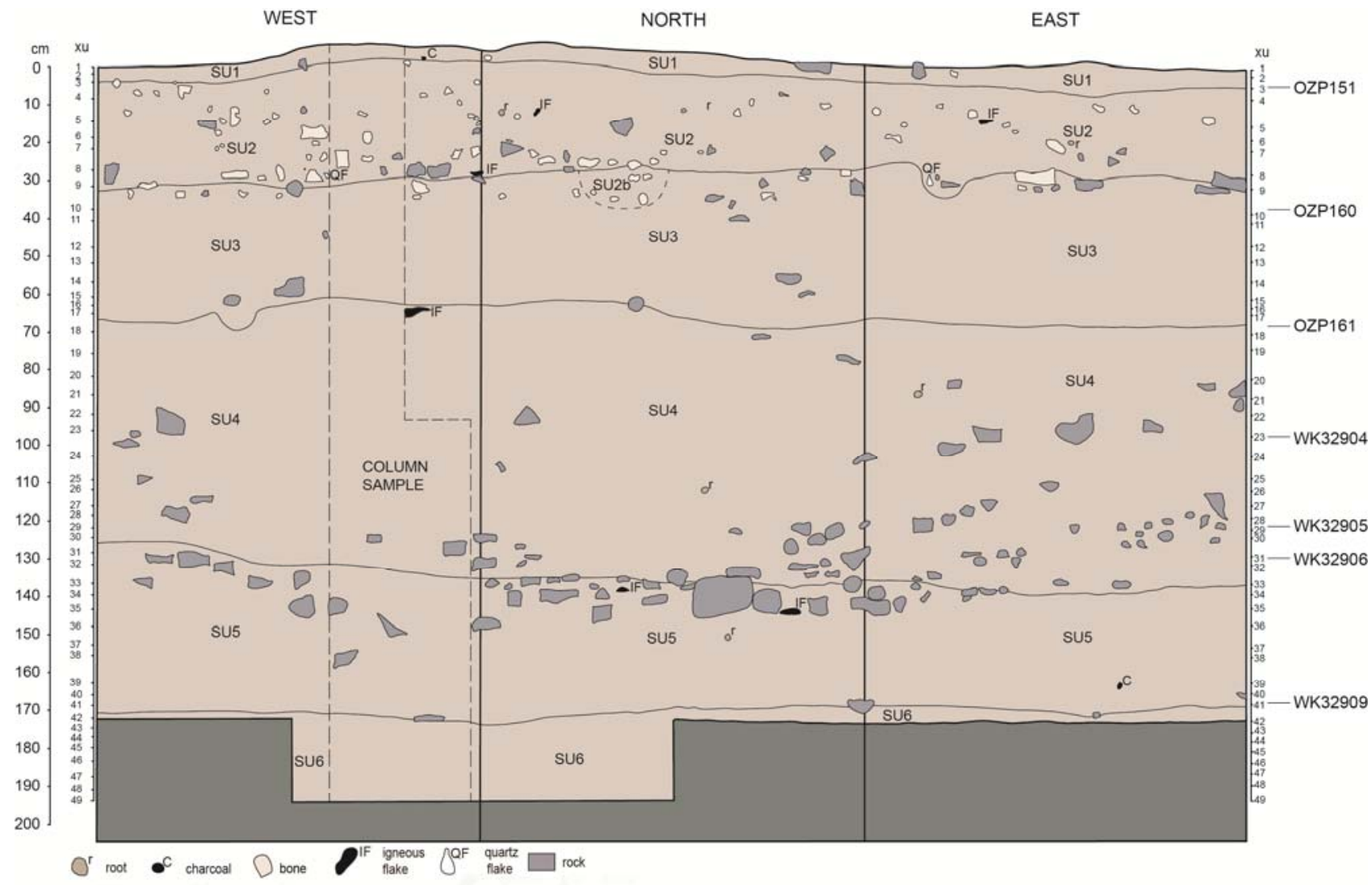

Figure 4. Stratigraphic drawing for Square C, Dabangay.

\section{Stratigraphy and Sediments}

Six stratigraphic units (SUs) were identified, with a change with depth from very dark grey, humic soil (Munsell= 7.5YR 3/1) to brown-pinkish grey, calcareous sand (Munsell= 7.5YR 5/4 to 7.5YR 6/2) (Figure 4). A gradation was observed between mottled, silty sand (SUs 3-4) to coarse-grained, cemented, white-yellow sand (SUs 5-6). A pH test showed that sediments were mildly acidic (4.14-5.13), with increased acidity in the basal cemented sand.

Clear stratigraphic boundaries and intact lenses of pumice, ochre, stone and bone suggest overall stratigraphic integrity. In contrast to Square A, termite activity was not observed, with disturbance restricted to a single, small pit feature at the interface between SU2 and SU3. This SU2b feature was excavated separately along with a 3cm-wide buffer (Figure 4). A small, glass flake was excavated from XU20. We suggest this specimen fell from the wall during excavation and does not indicate substantial vertical movement of material within the deposit. This is supported by the absence of European materials in mid-Holocene layers, the sequential radiocarbon dates and horizontal orientation of many bones and stones.

\section{Radiocarbon Dates and Chronology}

Thirteen in situ samples of wood charcoal and hardwood were submitted to the Waikato Radiocarbon Dating Laboratory and Australian Nuclear Science and Technology Organisation (ANSTO) for radiocarbon AMS dating. Six samples (between 170-150cm BS) could not be dated as the material did not survive pretreatment, most likely a result of chemical weathering associated with ground-water infiltration (J. Peterson, pers. comm., 2006; F. Petchey, pers. comm., November 2010).

At Waikato charcoal was prepared in a bath of hot $10 \% \mathrm{HCl}$ and then further treated with hot $5 \% \mathrm{NaOH}$ before being filtered, rinsed and dried. At ANSTO charcoal was treated with $\mathrm{HCl}\left(2 \mathrm{M}, 60^{\circ} \mathrm{C}\right), \mathrm{NaOH}(3 \%$, $\left.60^{\circ} \mathrm{C}\right)$ and $\mathrm{HCl}\left(2 \mathrm{M}, 60^{\circ} \mathrm{C}\right)$ for 2 hours apiece. Samples were washed thoroughly with Milli-Q water and dried before combustion and conversion of the resulting carbon dioxide to graphite for AMS analysis. Radiocarbon dates were calibrated using OxCal 4.1 (Bronk Ramsey 2009) and the Southern Hemisphere calibration dataset (SHCal04) (McCormac et al. 2004).

Three settlement phases were observed, marked by quantitative and to a lesser extent qualitative shifts in cultural materials (Table 1). Phase 1 (SUs 6-4; 69383349 cal BP) is characterised by large quantities of charcoal and moderate quantities of lithics and faunal remains. Phase 2 (SU3; 3349-1684 cal BP) is represented by sparse cultural remains, albeit sufficient to indicate ongoing human presence. Phase 3 (SUs 2-1; 1684-306 cal BP) is characterised by a marked increase in all cultural materials. The upper part of Phase 3 contains European materials (nails, ceramic, glass, beads, clay pipe), which clustered between XUs 6-2 but were recovered in low numbers down to XU9, probably reflecting downward movement of heavier fragments of metal (the main component of XU9) during the period of European contact (henceforth 'PEC'). 
Table 1. AMS radiocarbon dates from Square C, Dabangay. NDA = no data available.

\begin{tabular}{|c|c|c|c|c|c|c|c|}
\hline Lab. No. & $\mathbf{X U}$ & $\begin{array}{c}\text { Depth } \\
\text { (cm) }\end{array}$ & $\begin{array}{c}\text { Sample/Weight } \\
\text { (g) }\end{array}$ & $\begin{array}{l}\delta^{13} \mathrm{C} \\
(\% \circ)\end{array}$ & $\begin{array}{c}{ }^{14} \text { C Age } \\
\text { (years BP) }\end{array}$ & $\begin{array}{c}\text { Calibrated Age BP } \\
68.3 \% \\
\end{array}$ & $\begin{array}{c}\text { Calibrated Age BP } \\
95.4 \% \\
\end{array}$ \\
\hline OZP159 & 3 & $2-4$ & Charcoal/0.16 & $-25.8 \pm 0.1$ & $240 \pm 25$ & $\begin{array}{c}296-279(23.1 \%) \\
205-195(12.9 \%) \\
187-180(8.1 \%) \\
171-154(24.1 \%)\end{array}$ & $\begin{array}{l}306-271(29.9 \%) \\
219-148(65.5 \%)\end{array}$ \\
\hline Wk-32909 & 10 & $27-31$ & Charcoal/0.21 & $-26.9 \pm 0.1$ & $1695 \pm 30$ & $\begin{array}{c}1600-1583(7.7 \%) \\
1570-1515(49.5 \%) \\
1459-1443(7.6 \%) \\
1431-1423(3.4 \%) \\
\end{array}$ & $\begin{array}{c}1684-1678(0.8 \%) \\
1615-1415(94.6 \%)\end{array}$ \\
\hline OZP161 & 18 & $67-70$ & Charcoal/0.18 & $-24.5 \pm 0.1$ & $3250 \pm 30$ & 3446-3383 (68.2\%) & $3480-3349$ (95.4\%) \\
\hline Wk-32904 & 23 & $100-104$ & Hardwood/0.22 & $-24.9 \pm 0.2$ & $3924 \pm 32$ & $\begin{array}{c}4406-4367(17.4 \%) \\
4357-4323(16.0 \%) \\
4317-4311(2.7 \%) \\
4304-4240(32.1 \%) \\
\end{array}$ & $\begin{array}{l}4415-4223(83.7 \%) \\
4205-4157(11.7 \%)\end{array}$ \\
\hline Wk-32905 & 29 & $120-125$ & Hardwood/1.64 & $-23.3 \pm 0.2$ & $4454 \pm 33$ & $\begin{array}{l}5037-5007(15.4 \%) \\
4980-4875(52.8 \%)\end{array}$ & $\begin{array}{c}5268-5222(3.1 \%) \\
5215-5186(4.2 \%) \\
5120-5112(0.5 \%) \\
5064-4855(87.6 \%)\end{array}$ \\
\hline Wk-32906 & 31 & $130-132$ & Hardwood/0.2 & NDA & $4359 \pm 34$ & $\begin{array}{l}4958-4832(11.4 \%) \\
4883-4832(56.8 \%) \\
\end{array}$ & $\begin{array}{c}5028-5021(0.7 \%) \\
4974-4825(94.7 \%) \\
\end{array}$ \\
\hline Wk-32909 & 41 & $173-177$ & Acacia?/0.55 & $-24.6 \pm 0.2$ & $6052 \pm 29$ & 6889-6786 (68.2\%) & 6938-6742 (95.4\%) \\
\hline
\end{tabular}

\section{Cultural Materials}

Flaked stone artefacts dominate the assemblage $(\mathrm{n}=8522)$ with two igneous hammer stones and one anvil also recorded. In addition, Square C contained large amounts of marine vertebrate bone $(11.6 \mathrm{~kg})$ and charcoal $(1.4 \mathrm{~kg})$ and smaller quantities of fish bone (109.3g), turtle (1.1g), molluscs (13.7g) and European materials (mainly metal and glass).

\section{Stone Artefacts}

Crystal and good quality vein quartz dominate the Dabangay assemblage ( $94 \%$ of total; $n=8019)$. In addition there are 506 artefacts (totalling 6\%) made from local igneous rock and 17 glass flakes. With the exception of two igneous hammers and one igneous anvil, the assemblage consists of flakes, cores and flaked pieces. Bipolar hammers and anvils were found in XU6 and XU30 respectively. Pounding surfaces are deeply pitted suggesting repeated use. Retouched flakes were rare, totalling only 8 out of 8517 flaked artefacts. A large number of cores were identified in the collection, including 137 quartz cores and 13 igneous cores. The majority of cores are bipolar.

Artefact discard is highest between XUs 11-2 (90\% of total), with major peaks in XUs 2, 7 and 9 (41\% of total) (Figure 5). Lithic quantities decline steadily below this until a 'background' level is reached in XU16. Less than $6 \%$ of the total artefact assemblage (relative to amount of material excavated) occurs between XUs 41-16, typically between 9 and 30 artefacts per XU. Numbers are particularly low between XUs 27-16 with a slight increase between XUs 38-28. No lithics were recorded below XU41.

There is evidence for both consistency and change in the vertical distribution of artefacts. Quartz and igneous lithics continue throughout the assemblage, with quartz flakes being consistently small, highly reduced and lacking cortex while igneous flakes were often larger with cortex remaining. Quartz flake size increased marginally in the upper layers, although this may reflect the larger sample size in these layers. Analysis indicates consistent use of hand-held reduction for quartz and igneous artefacts, followed by bipolar reduction as core size diminished. Bipolar techniques continued throughout the sequence with varying levels of reduction. The lowest level with a bipolar core is XU37. Small numbers of retouched flakes (made through opportunistic flake removal) occurred in upper and lower layers of Square C. Detailed lithic analysis (e.g. materials, size variation and reduction processes) will be reported in a future publication.

Raw material abundance shows a distinct chronological trend, expressed in the ratio of quartz:igneous (Figure 6; Table 2). Igneous is relatively common below XU20 (with the exception of XU38) and in XU2, whereas XUs 19-3 have proportionally more quartz to igneous artefacts. A $67 \%$ reduction in the quantity of igneous artefacts occurs between SU5 and SU4 while quartz reduced by $23 \%$ in these SUs.

All glass artefacts came from the top six XUs (16 within $20 \mathrm{~cm}$ of the surface) with the exception of a single, intrusive glass flake at $80 \mathrm{~cm}$ (XU20). This is consistent with other non-artefactual European materials, suggesting the major phase of European activity occurred during the build-up of sediments between XUs 6-2.

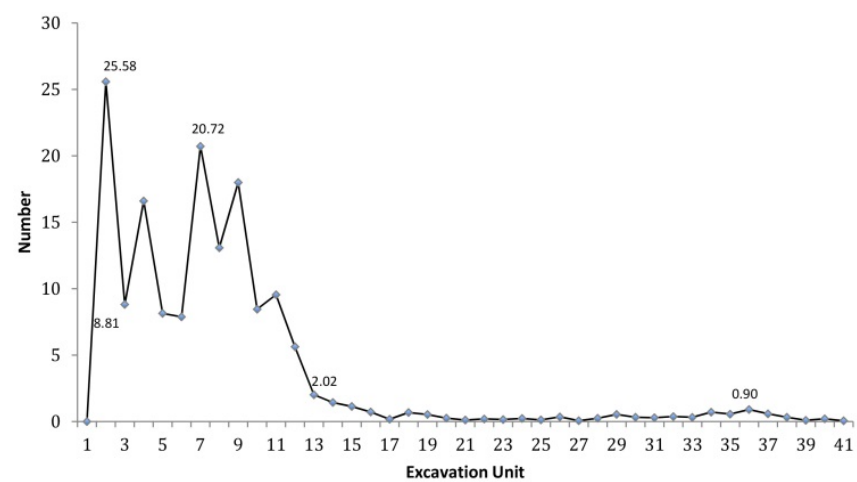

Figure 5. Number of stone artefacts/litre from Square C, Dabangay. 
Table 2. Artefacts (including ratio of quartz(Q):igneous(I) lithics) from Square C, Dabangay.

\begin{tabular}{|c|c|c|c|c|c|c|c|c|c|c|c|c|c|c|c|c|}
\hline $\mathbf{X U}$ & Q Flakes & Q Cores & Q FP & Q Ret & Q Total & I Flakes & I Cores & I FP & I Ret & I Total & Hammers & Anvil & Total Stone & Glass & Total All & Ratio Q to I \\
\hline 1 & 0 & 0 & 0 & 0 & 0 & 0 & 0 & 0 & 0 & 0 & 0 & 0 & 0 & 0 & 0 & NA \\
\hline 2 & 795 & 20 & 7 & 0 & 822 & 117 & 0 & 0 & 0 & 117 & 0 & 0 & 939 & 5 & 944 & 7.03 \\
\hline 3 & 489 & 19 & 19 & 1 & 528 & 19 & 0 & 0 & 0 & 19 & 0 & 0 & 547 & 3 & 550 & 27.79 \\
\hline 4 & 829 & 18 & 8 & 1 & 856 & 64 & 0 & 0 & 0 & 64 & 0 & 0 & 920 & 5 & 925 & 13.38 \\
\hline 5 & 584 & 8 & 1 & 0 & 593 & 14 & 2 & 0 & 0 & 16 & 0 & 0 & 609 & 1 & 610 & 37.06 \\
\hline 6 & 418 & 14 & 2 & 0 & 434 & 26 & 0 & 1 & 1 & 28 & 2 & 0 & 462 & 2 & 468 & 15.50 \\
\hline 7 & 732 & 10 & 0 & 0 & 742 & 0 & 5 & 1 & 0 & 6 & 0 & 0 & 748 & 0 & 748 & 123.67 \\
\hline 8 & 1003 & 13 & 6 & 0 & 1022 & 49 & 0 & 0 & 0 & 49 & 0 & 0 & 1071 & 0 & 1071 & 20.86 \\
\hline 9 & 932 & 3 & 0 & 0 & 935 & 40 & 1 & 0 & 3 & 44 & 0 & 0 & 979 & 0 & 979 & 21.25 \\
\hline 10 & 607 & 6 & 0 & 0 & 613 & 5 & 0 & 0 & 0 & 5 & 0 & 0 & 618 & 0 & 618 & 122.60 \\
\hline 11 & 417 & 8 & 0 & 0 & 425 & 21 & 1 & 0 & 0 & 22 & 0 & 0 & 447 & 0 & 447 & 19.32 \\
\hline 12 & 329 & 3 & 0 & 0 & 332 & 20 & 0 & 0 & 0 & 20 & 0 & 0 & 352 & 0 & 352 & 16.60 \\
\hline 13 & 123 & 0 & 0 & 0 & 123 & 4 & 0 & 0 & 0 & 4 & 0 & 0 & 127 & 0 & 127 & 30.75 \\
\hline 14 & 65 & 0 & 0 & 0 & 65 & 4 & 0 & 0 & 0 & 4 & 0 & 0 & 69 & 0 & 69 & 16.25 \\
\hline 15 & 58 & 0 & 0 & 0 & 58 & 4 & 0 & 0 & 0 & 4 & 0 & 0 & 62 & 0 & 62 & 14.50 \\
\hline 16 & 24 & 0 & 0 & 0 & 24 & 1 & 0 & 0 & 0 & 1 & 0 & 0 & 25 & 0 & 25 & 24.00 \\
\hline 17 & 4 & 0 & 0 & 0 & 4 & 0 & 0 & 0 & 0 & 0 & 0 & 0 & 4 & 0 & 4 & \\
\hline 18 & 39 & 0 & 0 & 0 & 39 & 0 & 0 & 0 & 0 & 0 & 0 & 0 & 39 & 0 & 39 & \\
\hline 19 & 24 & 0 & 0 & 0 & 24 & 1 & 0 & 0 & 0 & 1 & 0 & 0 & 25 & 0 & 25 & 24.00 \\
\hline 20 & 24 & 1 & 0 & 0 & 25 & 3 & 0 & 0 & 0 & 3 & 0 & 0 & 28 & 1 & 29 & 8.33 \\
\hline 21 & 8 & 0 & 0 & 0 & 8 & 1 & 0 & 0 & 0 & 1 & 0 & 0 & 9 & 0 & 9 & 8.00 \\
\hline 22 & 14 & 0 & 0 & 0 & 14 & 3 & 0 & 0 & 0 & 3 & 0 & 0 & 17 & 0 & 17 & 4.67 \\
\hline 23 & 10 & 0 & 0 & 0 & 10 & 0 & 0 & 0 & 0 & 0 & 0 & 0 & 10 & 0 & 10 & \\
\hline 24 & 19 & 1 & 1 & 0 & 21 & 2 & 0 & 0 & 0 & 2 & 0 & 0 & 23 & 0 & 23 & 10.50 \\
\hline 25 & 9 & 0 & 0 & 0 & 9 & 0 & 0 & 0 & 0 & 0 & 0 & 0 & 9 & 0 & 9 & \\
\hline 26 & 13 & 0 & 0 & 0 & 13 & 1 & 0 & 0 & 0 & 1 & 0 & 0 & 14 & 0 & 14 & 13.00 \\
\hline 27 & 4 & 0 & 0 & 0 & 4 & 0 & 0 & 0 & 0 & 0 & 0 & 0 & 4 & 0 & 4 & \\
\hline 28 & 6 & 3 & 1 & 0 & 10 & 7 & 0 & 0 & 0 & 7 & 0 & 0 & 17 & 0 & 17 & 1.43 \\
\hline 29 & 27 & 0 & 1 & 0 & 28 & 8 & 2 & 0 & 0 & 10 & 0 & 0 & 38 & 0 & 38 & 2.80 \\
\hline 30 & 11 & 1 & 0 & 0 & 12 & 1 & 1 & 0 & 0 & 2 & 0 & 1 & 14 & 0 & 14 & 6.00 \\
\hline 31 & 13 & 1 & 0 & 0 & 14 & 1 & 0 & 1 & 0 & 2 & 0 & 0 & 16 & 0 & 16 & 7.00 \\
\hline 32 & 16 & 0 & 0 & 0 & 16 & 10 & 0 & 0 & 0 & 10 & 0 & 0 & 26 & 0 & 26 & 1.60 \\
\hline 33 & 15 & 2 & 1 & 0 & 18 & 8 & 0 & 0 & 0 & 8 & 0 & 0 & 26 & 0 & 26 & 2.25 \\
\hline 34 & 26 & 2 & 0 & 0 & 28 & 9 & 0 & 0 & 1 & 9 & 0 & 0 & 37 & 0 & 37 & 3.11 \\
\hline 35 & 28 & 4 & 0 & 0 & 32 & 13 & 0 & 0 & 0 & 13 & 0 & 0 & 45 & 0 & 45 & 2.46 \\
\hline 36 & 42 & 0 & 1 & 0 & 43 & 13 & 1 & 0 & 0 & 14 & 0 & 0 & 57 & 0 & 57 & 3.07 \\
\hline 37 & 33 & 0 & 0 & 1 & 34 & 12 & 1 & 0 & 0 & 13 & 0 & 0 & 47 & 0 & 47 & 2.62 \\
\hline 38 & 22 & 0 & 0 & 0 & 22 & 1 & 0 & 0 & 0 & 1 & 0 & 0 & 23 & 0 & 23 & 22.00 \\
\hline 39 & 9 & 0 & 1 & 0 & 10 & 0 & 0 & 0 & 0 & 0 & 0 & 0 & 10 & 0 & 10 & \\
\hline 40 & 6 & 1 & 0 & 0 & 7 & 2 & 0 & 0 & 0 & 2 & 0 & 0 & 9 & 0 & 9 & 3.50 \\
\hline 41 & 2 & 0 & 0 & 0 & 2 & 1 & 0 & 0 & 0 & 1 & 0 & 0 & 3 & 0 & 3 & 2.00 \\
\hline
\end{tabular}




\section{Marine Vertebrates}

The faunal assemblage consists of a substantial quantity of highly fragmented bone from one or more large marine vertebrates $(11.55 \mathrm{~kg})$, and smaller quantities of fish bone (109.29g) and turtle (1.07g). No terrestrial or volant (e.g. birds, bats) vertebrate remains were recovered from Square C.

The large vertebrate remains from Mabuyag are highly fragmented and only a small proportion can be assigned to anatomical elements and taxa. With the exception of two small fragments of what appear to be turtle carapace (XUs 6, 2) all diagnostic pieces of large vertebrate bone derive from dugongs (Dugong dugon). We are confident that at least the large majority of the remains can be assigned to this taxon.

All small vertebrate bone from Square C is derived from fishes, including representatives of at least four families, with Labridae (wrasses) and Scaridae (parrot fishes) dominant throughout the sequence, and Carangidae (jacks) and Lethrinidae (emperors) only sporadically represented. Most are small-to-medium sized fish, with the exception of occasional large labrids. The degree of fragmentation of the fish remains precludes meaningful estimation of relative abundances, as the majority of dentigerous elements are fragmented. Shark teeth occur sporadically through the profile. The majority derive from small sharks. A more detailed analysis of the fish remains will appear in a future publication.

Dugong bone was restricted to XUs 19-2 (maximum span=4223 cal BP-PEC) with only small quantities (total= 20.53g) found below XU13 (Figure 7). By contrast, the vertical distribution of fish bone shows two well-separated peaks, one broadly spread across XUs 2920 (maximum span=5268-3349 cal BP) and a second concentrating between XUs 10-2 (maximum span=1684 cal BP-PEC), but continuing to XU13 (Figure 8). Only small quantities (total $=1.7 \mathrm{~g}$ ) of bone were recovered in XUs 19-14 and between XUs 29-31.

In Square C, bone from XUs 10-2 (SUs 2-1) appears well-preserved and includes a high proportion of unburnt remains. Between XUs 26-11 (SUs 4-3) the unburnt remains are visibly degraded and a higher proportion of the bone is burnt, both good indicators of microbial degradation of the organic components of bone. Below XU27 (SU5) virtually all of the remains are calcined. Calcined bone is the product of prolonged burning at very high temperatures $\left(>800^{\circ} \mathrm{C}\right.$; Brain 1993) and is normally only produced through cultural activity. Its persistence when all other bone has degraded is due to the complete destruction during firing of organic content, thereby rendering it stable in most environments.

\section{Marine Invertebrates}

The Square C mollusc assemblage (13.7g) was highly fragmented, with no MNI diagnostic taxa observed and this meant that no shellfish could be classified as economic. Most shellfish (13.6g of total) came from the top of SU2 and SU1 (i.e. XUs 7-1) with two small fragments located in XUs 28 and 16. In addition, three crab claws were excavated, one in XU23 and two in XU8. The small size of the crabs suggests a non-cultural origin.

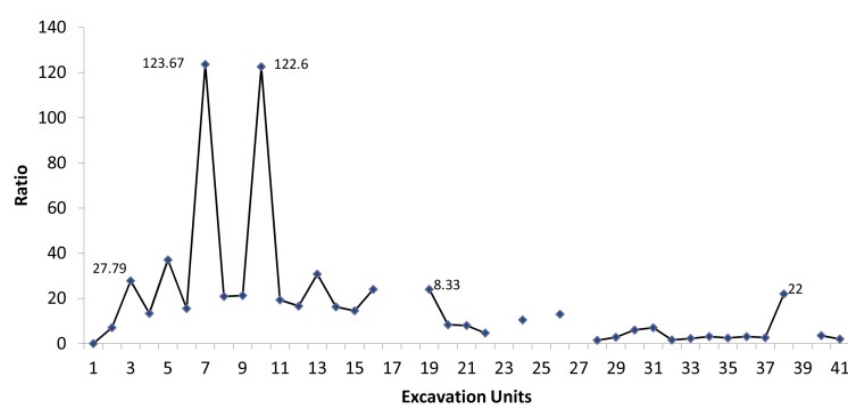

Figure 6. Ratio of quartz to igneous artefacts from Square C, Dabangay.

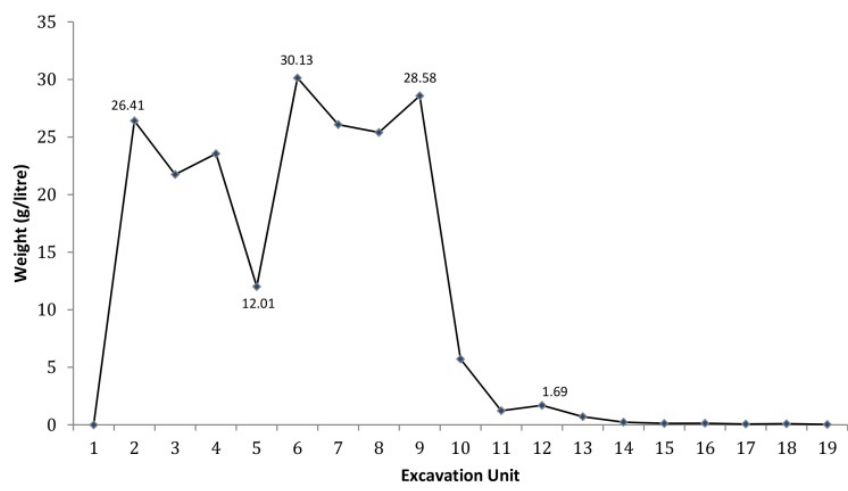

Figure 7. Weight of dugong bone from Square C, Dabangay. No large marine vertebrate remains were found below XU19.

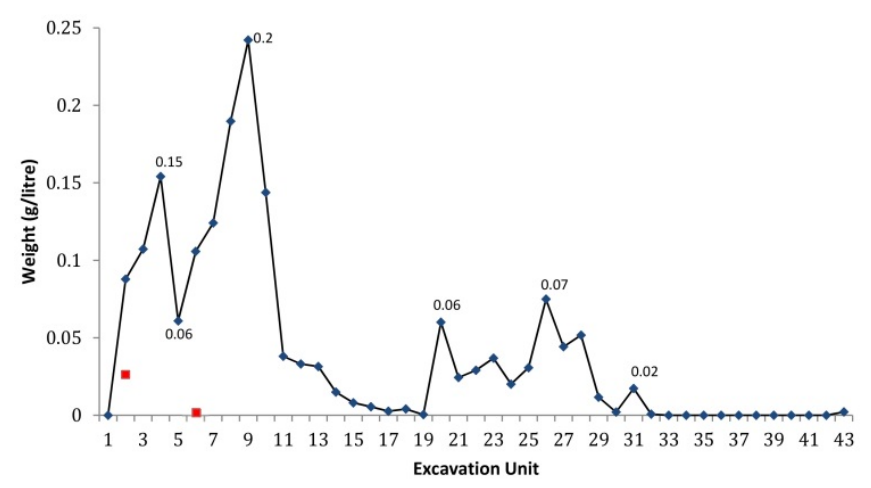

Figure 8. Weight of fish bone (diamond) and turtle (square) from Square C, Dabangay.

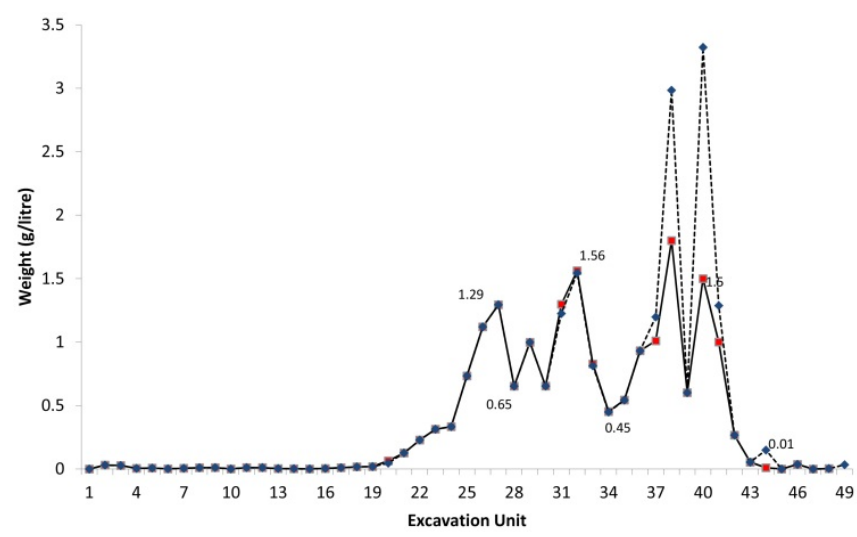

Figure 9. Weight of charcoal with (square markers) and without (diamond markers) removal of calcined samples through floatation from Square C, Dabangay. 


\section{Charcoal}

Large quantities of charcoal $(1.4 \mathrm{~kg})$ were excavated at Dabangay, the majority of which $(1.36 \mathrm{~kg})$ occurred between XUs 41-26 (SUs 6, 5 and base of 4) (Figure 9). Charcoal was present in significantly reduced quantities in SUs 3, 2, 1 and in basal XUs 49-42. In SU6 (XU4937 ) the weight of some charcoal samples was observed to have increased due to absorption of calcite. Removal of these samples through careful analysis and floatation does not substantially alter results with $1.22 \mathrm{~kg}$ excavated between XUs 41-26. The consistently large size of many charcoal fragments suggests localised burning.

\section{European Materials}

European materials included fragments of glass, metal, ceramics, clay pipe and beads. Excluding one specimen that we conclude was displaced during excavation (see previous section on lithics), these were restricted to the upper nine XUs with the main concentration between XUs 6-1 (Figure 10). Artefacts below XU6 include two small pieces of glass and three unidentifiable fragments of iron alloy and lead.

Most glass fragments (5 out of $6, \mathrm{MNI}=1$ ) were identified as body sherds from wine or beer bottles ( $P$. Ricardi, pers. comm., November 2012). In addition there were two near spherical seed beads (XU3), a two-toned German marble (XU4), two fragments of unidentified clay pipe (XUs 2, 4), one piece of glazed white stoneware (XU4), two bird size pellets of lead shot (XUs 2, 3) and iron alloy and steel nails (XUs 2, 3).

Clay pipe fragments are consistent with examples recorded during a surface collection that date from midto-late nineteenth century. Steel patent machine cut nails are likely to post-date 1890 (Burke and Smith 2004:378) while stoneware was consistent with British ceramics from Mua which dated to from the late nineteenth or early twentieth centuries (Ash and David 2008:476). One of the two beads was classified as 'Cornaline d'Aleppo, white heart'. This form was devised by the Venetians in about 1825 and appeared in the North American archaeological horizon from c.1830 (J. Allen, pers. comm., April 2012). The Dabangay bead has been provisionally dated to between 1830-1860 (J. Allen, pers. comm., 24 April 2012); however, it may have been curated for many years prior to arrival on Mabuyag.

\section{Pumice and Ochre}

Ochre was recovered from all SUs, reaching a depth of XU36. The majority of ochre clustered between XUs 10 2 (90.5\% of total weight), with a further $8.8 \%$ between XUs 36-27. Pumice was found in all layers, with the greatest density between XUs 10-2 (73.6\% of total weight). A lens of pumice in XU16 contained 14\% of the total weight (9.1g).

\section{Square B}

Square B $\left(1 \mathrm{~m}^{2}\right)$ was situated deep in the embayment, to test the spread of cultural activity across Dabangay (Figure 3). Excavation methods were consistent with Square C. Excavation units averaged $3.1 \mathrm{~cm}$, with the square discontinued after $105 \mathrm{~cm}$ below surface before culturally sterile deposits were reached (see above). Analysis of Square B remains incomplete and so results should be viewed as preliminary.

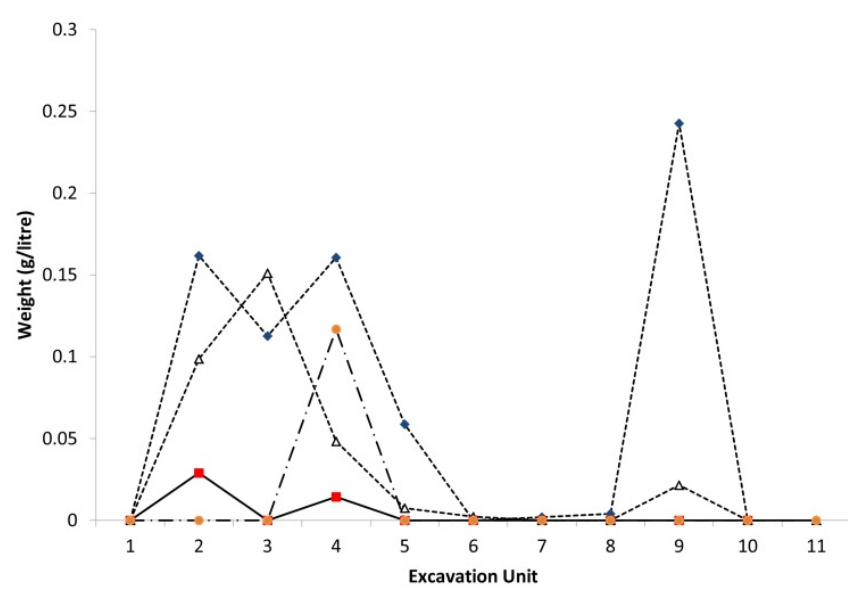

Figure 10. Weight of European materials from Square C, Dabangay. Metal (diamond marker), clay pipe (square marker), glass (triangle marker), porcelain (circle marker).

\section{Stratigraphy}

Five stratigraphic units were observed, with minimal variation in sediment colour and texture (Figure 11). With the exception of a fine layer of dark, organic top-soil, compacted clay continued to the base, grading from finegrained, patchy clay (SUs 3-2) to clay and gravel (SU 4). $\mathrm{pH}$ results were similar to those obtained from Square C, with sediment mildly acidic (4.14-5.46). There was no visible trend in $\mathrm{pH}$ with depth. Compacted sediment and lenses of sandstone gravel, granite rocks and charcoal suggests stratigraphic integrity. Localised disturbance was observed in SU2, with sediment from a termite burrow (SU2b) excavated separately and discarded.

\section{Radiocarbon Chronology}

Four AMS radiocarbon determinations were obtained using methods previously described (Table 3). Results suggest three phases of human activity. Phase 1 (base of SU4; prior to 3398 cal BP) was associated with charcoal and (less securely) lithics; Phase 2 (SUs 4-3; 3398-1815 cal BP) was marked by reduction in cultural materials and Phase 3 (SUs 2-1; 1815 cal BP-PEC) contained the bulk of cultural materials, including $99 \%$ of large vertebrate bone and $97 \%$ of fish bone. A major peak in large and small vertebrate bone occurs above XU4 (associated with European materials) suggesting the majority of the cultural material post-dates 200 years ago.

\section{Cultural Materials}

Preliminary analysis suggests large marine vertebrate bone $(4.488 \mathrm{~kg})$ and flaked stone artefacts $(2.1 \mathrm{~kg})$ dominate the assemblage. Small quantities of dugong bone (86.3g), fish (59.6g), non-economic shellfish (18g) and European materials (0.4g) were recorded.

\section{Stone Artefacts}

Detailed analysis has not been completed for Square B. Preliminary results suggest the assemblage consists entirely of flaked quartz and igneous artefacts, with no grinding stones or anvils. By weight, artefacts cluster between XUs 9 and 2 (1.785kg; 85\% of total by weight; 1815 cal BP-PEC) and XUs 25-23 (130g; 7\%; 3211 cal BP) (Figure 12). These patterns may reflect the rudimentary nature of current analyses. 


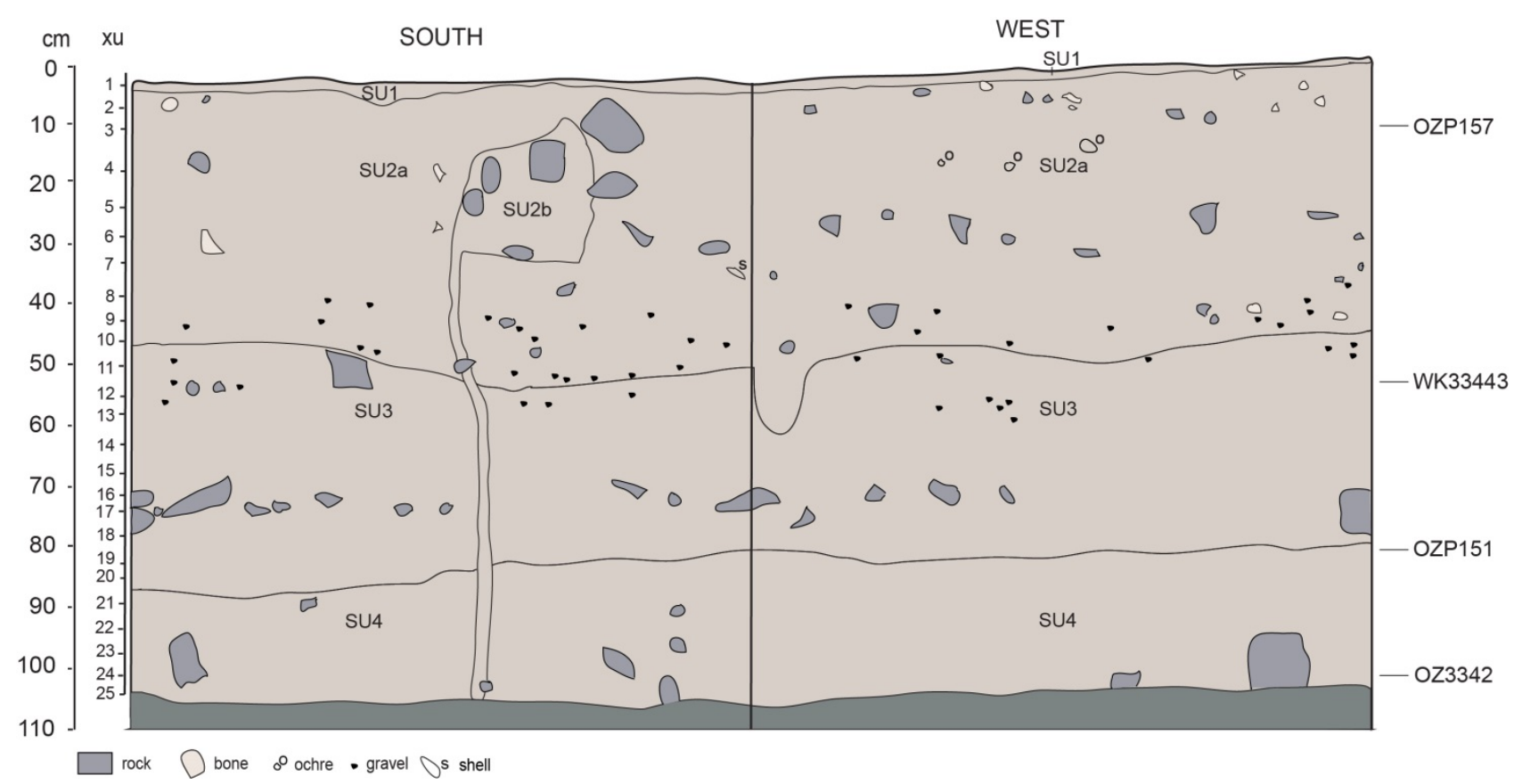

Figure 11. Stratigraphic drawing for Square B, Dabangay.

Table 3. AMS radiocarbon dates from Square B, Dabangay.

\begin{tabular}{|c|c|c|c|c|c|c|c|}
\hline Lab. No. & $\mathbf{X U}$ & $\begin{array}{l}\text { Depth } \\
\text { (cm) }\end{array}$ & $\begin{array}{c}\text { Sample/Weight } \\
\text { (g) }\end{array}$ & $\begin{array}{l}\delta^{13} \mathrm{C} \\
(\%)\end{array}$ & $\begin{array}{c}{ }^{14} \mathrm{C} \text { Age } \\
\text { (years BP) }\end{array}$ & $\begin{array}{c}\text { Calibrated Age BP } \\
68.3 \% \\
\end{array}$ & $\begin{array}{c}\text { Calibrated Age BP } \\
95.4 \%\end{array}$ \\
\hline OZP159 & 4 & $13-17$ & Charcoal/0.1 & $-26.2 \pm 0.2$ & $95 \pm 25$ & $\begin{array}{c}238-232(4.2 \%) \\
137-115(23.9 \%) \\
60-27(40.0 \%)\end{array}$ & $\begin{array}{c}252-227(9.8 \%) \\
142-82(34.6 \%) \\
74-5(50.9 \%)\end{array}$ \\
\hline Wk-32909 & 12 & $51-55$ & Charcoal/0.2 & $-23.3+/-0.2$ & $1833 \pm 25$ & $\begin{array}{l}1736-1687(35.0 \%) \\
1674-1621(33.2 \%) \\
\end{array}$ & $1815-1611(95.4 \%)$ \\
\hline OZP161 & 20 & $83-85$ & Charcoal/0.6 & $-28.2+/-0.3$ & $3150 \pm 35$ & $\begin{array}{l}3367-3317(38.1 \%) \\
3308-3264(30.1 \%) \\
\end{array}$ & 3398-3211 (95.4\%) \\
\hline Wk-32904 & 25 & 101-103 & Charcoal/0.1 & $-24.6+/-0.2$ & $5115 \pm 25$ & $\begin{array}{c}5891-5842(30.6 \%) \\
5832-5804(17.7 \%) \\
5794-5783(6.2 \%) \\
5770-5748(13.6 \%)\end{array}$ & $5907-5728(95.4 \%)$ \\
\hline
\end{tabular}




\section{Marine Vertebrates}

The faunal assemblage contains large vertebrate bone (4573.81g) including dugong and turtle, and smaller quantities (59.56g) of fish bone. No terrestrial vertebrate bones were recovered from Square B. Fish and dugong bone were compressed within the upper 20cm (XUs 5-1) of deposit (PEC) in Square B (Figures 13-14). Fish bone was prominent above XU11 (1815 cal BP-PEC, continuing in small quantities to the base of excavation. Bone preservation is best between XUs 4-1, with poor preservation, and increased burning observed below.

\section{Charcoal}

Small quantities of charcoal (29.5g) were excavated from Square B (Figure 15). Two peaks occur, the first between XUs 3-1 (11.51g; PEC) and a second between XUs 2523 (9.21g; 5907-3211 cal BP) at which stage large fragments occur. Charcoal was observed in reduced quantities in SUs 3 and 2.

\section{European Materials}

European materials were restricted to the upper three XUs. Three fragments of glass and four seed beads were recorded. The glass fragments $(\mathrm{MNI}=1)$ were identified as body sherds from wine or beer bottles of uncertain provenance (P. Ricardi, pers. comm., November 2012). The 'Cornaline d'Aleppo white heart' trade beads were provisionally dated to 1830-1860 (J. Allen, pers. comm., 24 April 2012).

\section{Discussion}

Re-excavation of Dabangay provides new insight into the antiquity and nature of human settlement on Mabuyag. Results suggest two principal phases of settlement (72393349 cal BP and 1815 cal BP-present), separated by a period of infrequent visitation between 3349-1815 cal BP (Figures 16-17). In keeping with historical records, human activity appears to increase during the past 200 years. The much shorter, late Holocene settlement chronology previously reported from Square A (300PEC) can now be attributed to termite disturbance. In Square B (and to a lesser extent Square C), a marked increase in the quantity of cultural materials is associated with the bulk of the European materials, thereby suggesting an increase in settlement intensity after European arrival (Figure 17). This is consistent with oral histories, which identify Dabangay as a significant village during the late nineteenth and early twentieth centuries.

Consistent with previous results, Phase 1 is associated with large quantities of charcoal and smaller quantities of lithics and bone. Most of the organic remains associated with Phase 1 have been lost through degradation processes, hence the small quantities of bone may not accurately depict the original assemblage. In Squares A and $\mathrm{C}$ the quantity of ochre peaks in layers dated to between 5000-6700 years ago; however, no additional fragments of ground stone were observed in Square B or C. During the past 1700 years, there was a substantial increase in the quantity of lithics, fish and marine vertebrates, the latter principally derived from dugong.

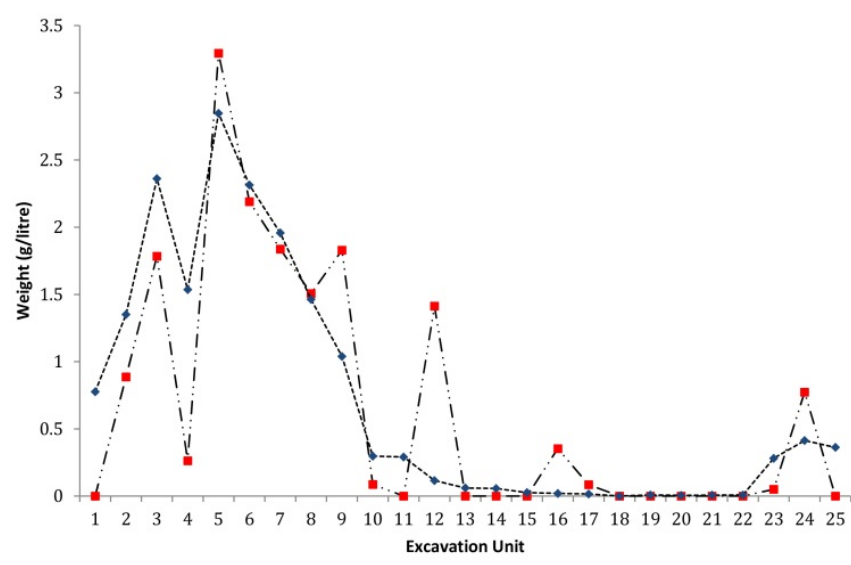

Figure 12. Weight of quartz (diamond markers) and igneous (square markers) lithics from Square B, Dabangay.

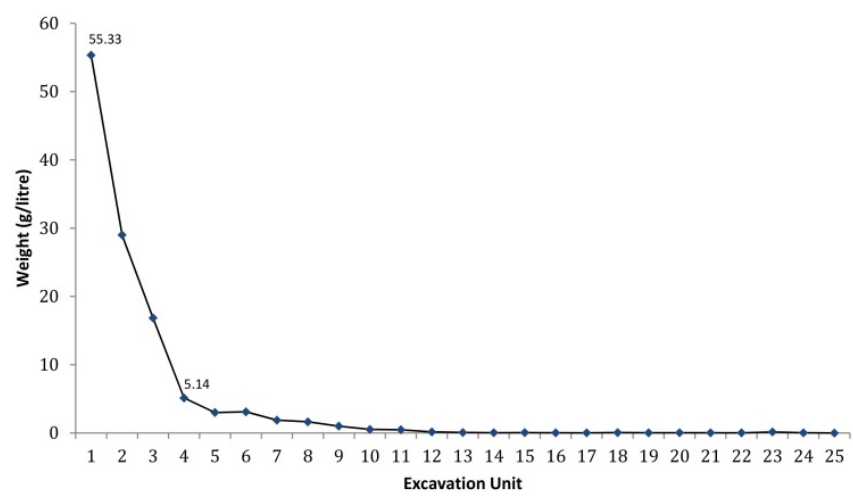

Figure 13. Weight of large vertebrate bone from Square B, Dabangay.

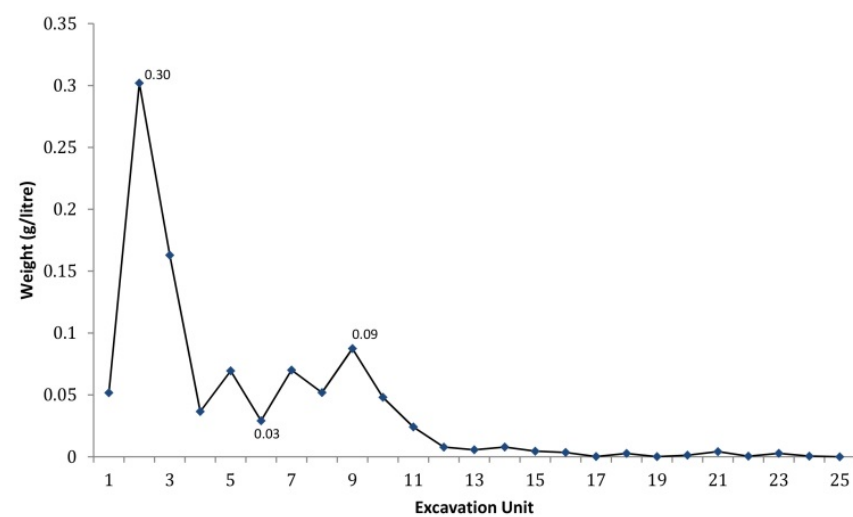

Figure 14. Weight of fish bone from Square B, Dabangay.

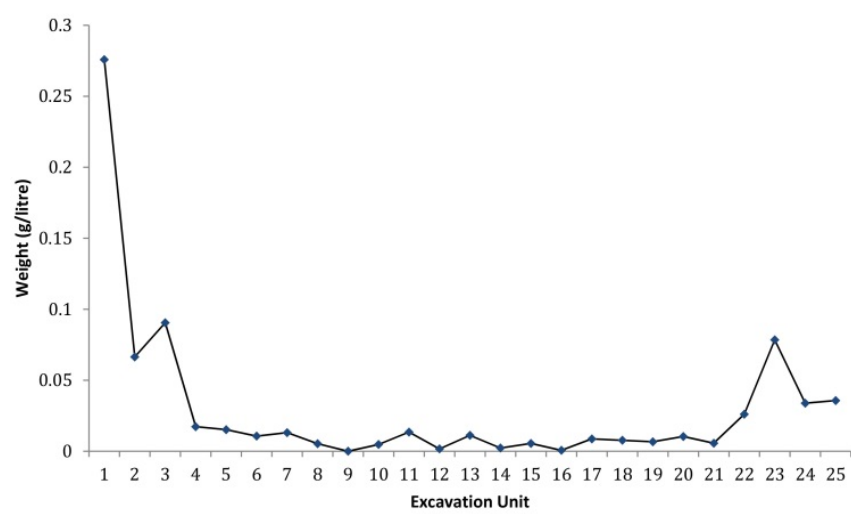

Figure 15. Weight of charcoal from Square B, Dabangay. 


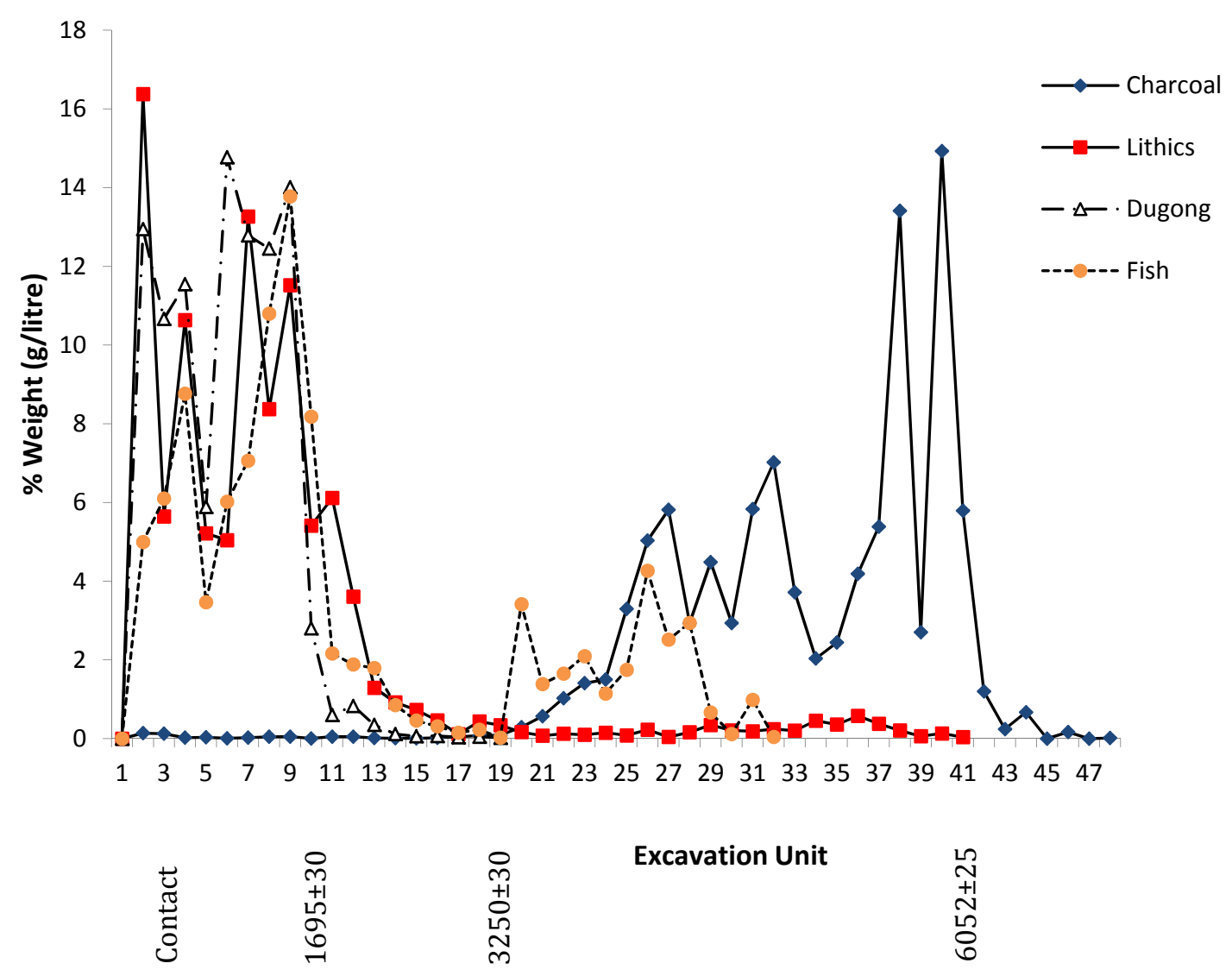

Figure 16. Distribution and chronology of cultural materials (percentage of total for each) excavated from Square C.

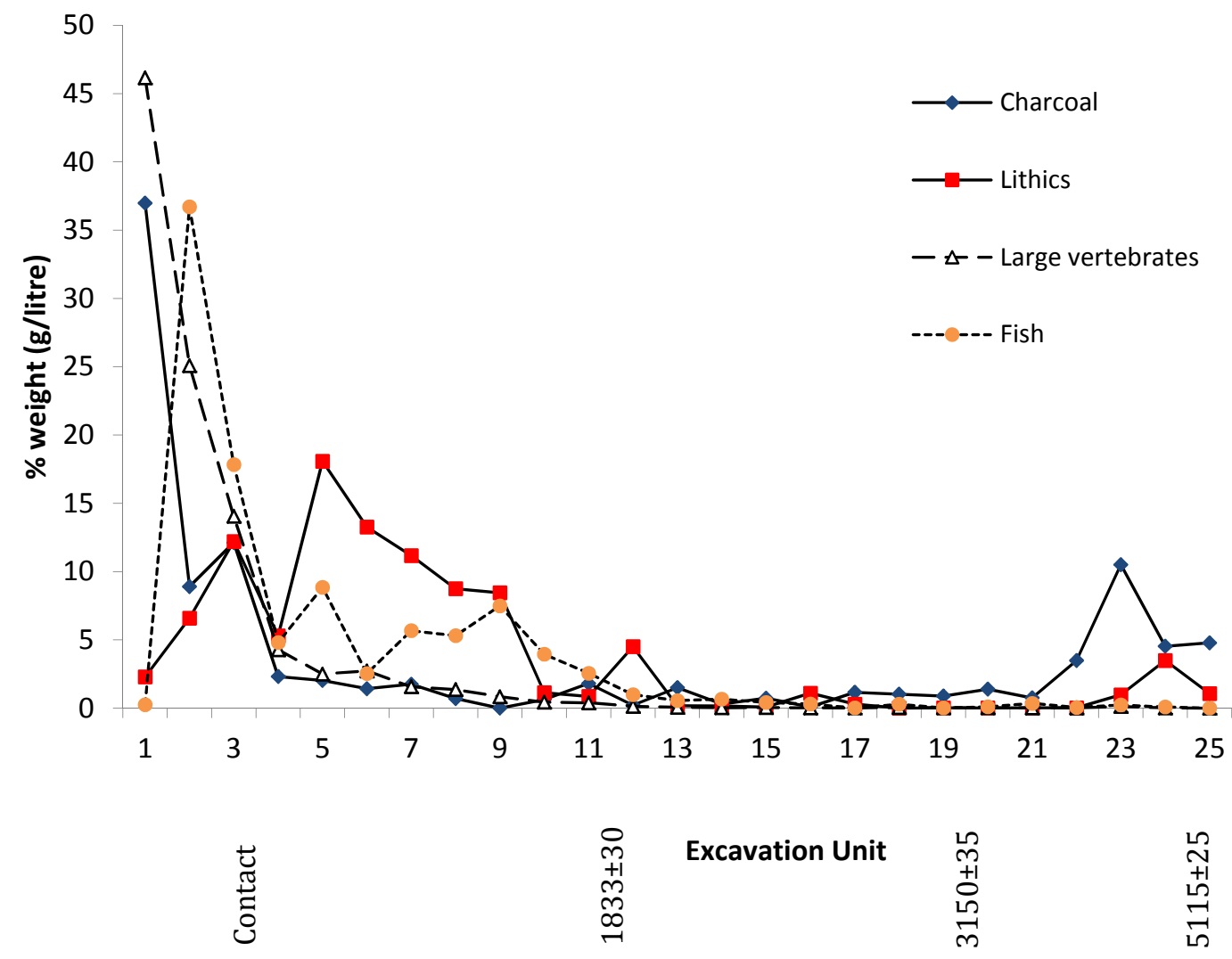

Figure 17. Distribution and chronology of cultural materials (percentage of total for each) excavated from Square B. 
While the purpose of this paper is not to examine the settlement chronology of Torres Strait (see Wright and Jacobsen 2013 for further details on chronology), we do offer one observation based on new data presented here. Previous papers suggested that marine transgression, 9000-8000 years ago, did not cause long-term abandonment of Torres Strait islands (Wright 2011; Wright and Jacobsen 2013). The Dabangay excavations support this view. Stable beaches and varied populations of large and small marine vertebrates were available in western Torres Strait from at least 7000 years ago (i.e. within 1000-2000 years of marine transgression). While many islands may have been abandoned during this period (cf. Barham 2000; Barham et al. 2004:57; David et al. 2004; Rowland 1985:131), we argue that the quantity, nature and distribution of mid-Holocene materials at Dabangay is consistent with frequent visitation and most likely sustained settlement rather than occasional visitation. In Square C, 416 lithics, 29.05g of fish bone and $1.51 \mathrm{~kg}(0.47 \mathrm{~g}$ per year) of charcoal were evenly distributed through layers dating between 6938 and 4157 cal BP. A similar density of mid-Holocene remains was observed in Square A and less securely in Square B, suggesting widespread human activity across the site during this period. This conclusion is further supported by the presence of highly reduced cores and specialised artefacts (e.g. anvil and ground stone) in SUs 5 and 6, in contrast to the absence of both in the subsequent period of low intensity site use (SU4). Confirmation of this scenario requires further geomorphological, palaeoenvironmental and archaeological work on western Torres Strait islands.

\section{Subsistence Change at Dabangay}

AMS-dated fragments of large vertebrate bone in Square A suggests low intensity hunting of these mammals between 7239-4888 cal BP (Wright 2011). The absence of dugong remains below XU19 in Square C and near absence below XU20 for Square B is unlikely to be a product of post-depositional degradation, as a proportion of the dugong remains in all levels is heavily burnt to calcined and equivalent remains from lower levels would be expected to have survived. Based on the small quantity (in SUs 6 and 5 of Square A and B) and absence (in SU4 of Square C) of large marine vertebrate bone, we suggest that dugong and turtle were not major components of the Islander diet until after approximately 4200-4000 years ago. This was followed by a major increase in the consumption of these animals after $1684 \mathrm{cal}$ BP and potentially also during the period of European contact after 200 years ago. This is consistent with dates for the onset of marine specialised activity at Mask Cave and Badu 19.

The vertical distribution of fish bone differs from that for large vertebrate bone. Square A shows peak quantities between XUs 9-3, with a broad secondary peak between XUs 25-14. All radiocarbon determinations from these XUs post-date 267 cal BP, however AMS inversions and stratigraphic observations suggest termite disturbance throughout these SUs. Fish bone continued in smaller quantities to the base of Square A, with a smaller peak between XUs 40-36. Square C has two, well-separated peaks, one broadly spread across XUs 10-2 (1685 cal BP-PEC) and a second spread across XUs 28-20 (52683349 cal BP) with small quantities of fish bone continuing until XU31. Square B shows a more compressed pattern, with the major peak in XUs 5-4 (the past 200 years) and the secondary peak between XUs 13-9 (1815-252 cal BP). Fish bones were found in small quantities to a depth of $119 \mathrm{~cm}(<5907 \mathrm{cal} \mathrm{BP})$.

The presence of fish bone across the site, in layers dating to within the past 7200 years, suggests that a subsistence economy principally based on fishing existed well before dugong and other large marine vertebrates became established in the Islander diet. The range of fishes taken (wrasses, parrotfish, jacks, emperors and sharks) as well as the small size of most individual fishes indicates long-term use of inshore reef environment, as suggested also for the assemblages from Badu 19 and Mask Cave (Crouch et al. 2007; McNiven et al. 2006). The absence of molluscs in mid-Holocene layers at Dabangay is also consistent with the record form Mask Cave. For Dabangay this most likely reflects differential preservation between mid- and late Holocene layers; however, it cannot be ruled out that environmental instability during the mid-Holocene marine transgression resulted in low natural diversity and abundance of shellfish in this region.

Harris and Ghaleb (1987:28) observed the superimposition of stone-bone-shell mounds over earth mounds associated with agriculture at Dabangay. While no radiocarbon dates were obtained from this context, the onset of midden activity at Dabangay is likely to pre-date 300 years ago (McNiven and Bedingfield 2008; Wright 2011). A maximum date of 800 years ago was obtained for mound-and-ditch fields at Woam on Saibai (Barham and Harris 1985), though an increase in sedimentation rate of an adjacent swamp after 1200 BP may reflect 'clearance, mound-and-ditch constructions or maintenance of agricultural field systems' (Barham et al. 2004:48). The antiquity of agricultural activity at Dabangay is likely to pre-date European activity at the site. How it relates to chronology established for the Saibai mound-and-ditch fields will require further research.

\section{Technological Change at Dabangay}

A key project aim was testing the extent of lithic variation at Dabangay. Consistent with previous research, we have identified continuities in lithic raw material selection, flake size and manufacturing techniques through the midto-late Holocene. This includes the continued presence of bipolar and retouched lithics throughout the sequence and a consistent size differentiation between igneous and quartz flaked artefacts. Changes observed at Badu 19 and Mask Cave, after 3800 years ago and 2500 years ago (i.e. shifts in artefact discard rates, bipolar reduction, artefact size), were not matched at Dabangay. A reduction in the intensity of visitation or occupation activity at Dabangay between 3349-1830 cal BP, and therefore lithic sample size, may have influenced our capacity to observe these changes.

At Dabangay a substantial increase in the ratio of quartz to igneous artefacts occurred after 4223 cal BP (XU21 in Square C), with the ratio increasing further after 1800 years ago (XU13). Similar patterns were observed at Berberass and Mask Cave (Crouch et al. 2007; McNiven et al. 2006). While it is problematic interpreting past cultures based on a single mid-Holocene site, it may be 
significant that this transition at XU21 is associated with a marked increase in the prominence of large and small vertebrate bone, and a marked reduction in the quantity of charcoal. Two cultural developments might have contributed to these patterns: (a) adoption of small, bipolar quartz technologies to assist butchering of marine vertebrates; and (b) decreased landscape clearance due to retreating mangroves and stabilising seas.

A traditional owner from Mabuyag, the late Tim Gizu (pers. comm., November 2006), suggested that quartz was used before metal knives for cutting through the hard outer fat of dugong. Alternative social and therapeutic roles for small quartz flakes have been provided by McNiven (2006:6). While the late Holocene site of Dauan 4 gave no cause to associate quartz bipolar technology with dugong exploitation, our observations for Dabangay suggest at least a chronological association between these cultural components. Detailed analysis of lithics (including residues) is required to test whether or not the association is also a functional one.

Dabangay shows a coincident decrease around 4200 years ago in the local production of large igneous lithics and charcoal. It is tempting to link this change to wider environmental changes occurring in western Torres Strait during the mid-to-late Holocene. Pollen analysis from Mua, Badu and Zurath demonstrated that Rhizophora sp. mangroves were present in western Torres Strait from 7000 to 6000 years ago, and further indicated that 'much of the island lowlands in Torres Strait' were populated by mangroves until sea-levels stabilised after 4000-3000 years ago (Rowe 2011:98). People resident at Dabangay prior to 4000 years ago may have had ready access to mangrove wood as fuel and may even have been forced to use slash and burn clearance to maintain living space in a context of an ecologically aggressive mangrove forest. These and other possible cultural and environmental scenarios will be tested by future geomorphological (e.g. sediment size and content) and palaeoenvironmental (e.g. pollen and phytolith) analyses.

After 2600-2500 years ago, a marked increase in lithic discard rates and shift towards fine-grained raw materials was observed on Pulu and Badu suggesting altered settlement and subsistence activities (Crouch et al. 2007; McNiven et al. 2006). No change was observed in lithic technologies at Dabangay, however, this may reflect reduced site use during this period. After 1800 years ago, an assemblage dominated by quartz, bipolar micro-cores and flakes is consistent with many other sites in western Torres Strait (McNiven 2006; McNiven et al. 2006).

\section{Conclusion}

Results from a second season of excavation at Dabangay indicate a number of significant transitions in technology and economy during the mid-to-late Holocene. After 4200 years ago, people started to exploit dugong in addition to nearshore fishes, and simultaneously showed an increased preference for production of quartz lithics. After 1800 1600 years ago a higher ratio of quartz to igneous artefacts occurred alongside a substantial increase in large marine vertebrates (dugong, shark and turtle), the diet perhaps supplemented by shellfish and agricultural produce. It is plausible that changes in lithic technologies and subsistence strategies at Dabangay and elsewhere in western Torres Strait reflect innovations in hunting and/or butchery by increasingly specialised maritime communities. The high nutritional value of dugong (Kwan et al. 2006) suggests improvements in dugong hunting would have major socio-demographic repercussions for Torres Strait Islanders. Such a scenario may have occurred on Mabuyag, Pulu and Badu after 4200 years ago. Additional developments after 2500 cal BP (e.g. Badu 19, Mask Cave) and 1800 cal BP (e.g. Dabangay, Goemu, Tigershark Rockshelter, Kurturniawak, Dauan 4) may represent continuing refinements by marine specialists. Innovations in lithic technologies may not directly relate to hunting or butchering but reflect broad socio-demographic and/or environmental changes occurring during these periods (cf. Barham 2000). Social and environmental considerations may have also influenced the development of regionally distinct economies or activity areas. Either way, Dabangay provides a 7200 year history of survival and innovation on western Torres Strait islands and adds to a growing literature on regionally complex and dynamic interactions between people and environment.

\section{Acknowledgements}

We would like to thank the Australian Institute of Aboriginal and Torres Strait Islander Studies (1000/1013046) for fieldwork funding, regrettably one of the last grants before this important scheme was put on hold, and the Australian Institute of Nuclear Sciences and Engineering (ALNGRA10028) for funding some of the radiocarbon dates. We thank the Mabuyag community for supporting research and the field crew: Beboy Whap, Lewis Bani, Paula Whap, Shannon Sutton and Matthew Coller for assisting with excavations. We thank Pamela Ricardi and Jamey Allen for advice on European cultural materials and Tim Gizu (sadly deceased) for sharing stories about Mabuyag, past and present. Jeremy Ash kindly reviewed a draft of this paper and Beverley Brigham (School of Geography and Environmental Sciences, Monash University) assisted with illustrations.

\section{References}

Ash, J. and B. David 2008 Mua 22: Archaeology at the old village site of Totalai. In B. David, L. Manas and M. Quinnell (eds), Gelam's Homeland: Cultural and Natural History of the Island of Mua, Torres Strait, pp.451-472. Memoirs of the Queensland Museum, Cultural Heritage Series 4. Brisbane: Queensland Museum.

Barham, A.J. 1999 The local environmental impact of prehistoric populations on Saibai Island, northern Torres Strait, Australia: Enigmatic evidence from Holocene swamp lithostratigraphic records. Quaternary International 59:71105.

Barham, A.J. 2000 Late Holocene maritime societies in the Torres Strait Islands, northern Australia - Cultural arrival or cultural emergence? In S. O'Connor and P. Veth (eds), East of Wallace's Line: Studies of Past and Present Maritime Cultures of the Indo-Pacific Region, pp.223-314. Modern Quaternary Research in Southeast Asia 16. Rotterdam: A.A Balkema.

Barham, A.J. and J. Chappell 2005 Geographic changes of coastal lowlands in the Papuan past. In A. Pawley, R. Attenborough, J. Golson and R. Hide (eds), Papuan Pasts: Cultural, Linguistic and Biological Histories of PapuanSpeaking Peoples, pp.522-539. Pacific Linguistics 572. Canberra: Research School of Pacific and Asian Studies, Australian National University. 
Barham, A.J. and D.R. Harris 1985 Relict field systems in the Torres Strait region. In I.S. Farrington (ed.), Prehistoric Intensive Agriculture in the Tropics, pp.247-283. British Archaeological Research International Series 232. Oxford: British Archaeological Research.

Barham, A.J., M. Rowland and G. Hitchcock 2004 Torres Strait Bepotaim: An overview of archaeological and ethnoarchaeological investigations and research. In I.J. McNiven and N. Quinnell (eds), Torres Strait Archaeology and Material Culture, pp.1-72. Memoirs of the Queensland Museum, Cultural Heritage Series 3. Brisbane: Queensland Museum.

Beckett, J.R. 1972 The Torres Strait Islanders. In D. Walker (ed.), Bridge and Barrier: The Natural and Cultural History of Torres Strait, pp.307-326. Canberra: Research School of Pacific and Asian Studies, Australian National University.

Brain, C.K. 1993. The occurrence of burnt bones at Swarkrans and their implications for the control of fire by early hominids. In C.K. Brain (ed.), Swartkrans: A Cave's Chronicle of Early Man, pp.229-242. Transvaal Museum Monograph 8. Transvaal: Transvaal Museum.

Bronk Ramsay, C. 2009 Bayesian analysis of radiocarbon dates. Radiocarbon 51(1):337-336.

Burke, H. and C. Smith 2004 The Archaeologist's Field Handbook. Crows Nest, NSW: Allen and Unwin Press.

Crouch, J., I.J. McNiven, B. David, C. Rowe and M. Weisler 2007 Berberass: Marine resource specialization and environmental change in Torres Strait during the past 4000 years. Archaeology in Oceania 42(2):49-64.

David, B., J.A. Crouch and U. Zoppi 2005 Historicizing the spiritual: $B u$ shell arrangements on the island of Badu, Torres Strait. Cambridge Archaeological Journal 15(1):7191.

David, B. and I.J. McNiven 2004 Western Torres Strait Cultural History Project: Research design and initial results. In I.J. McNiven and M. Quinnell (eds), Torres Strait Archaeology and Material Culture, pp.199-208. Memoirs of the Queensland Museum, Cultural Heritage Series 3. Brisbane: Queensland Museum.

David, B., I.J. McNiven, R. Mitchell, M. Orr, S. Haberle, L. Brady and J. Crouch 2004 Badu 15 and the PapuanAustronesian settlement of Torres Strait. Archaeology in Oceania 39(2):65-78.

David, B. and M.I. Weisler 2006 Kurturniaiwak (Badu) and the archaeology of villages in Torres Strait. Australian Archaeology 63:21-34.

Ghaleb, B. 1990 An Ethnoarchaeological Study of Mabuiag Island, Torres Strait, Northern Australia. Unpublished PhD thesis, University College London, London.

Haddon, A.C. (ed.) 1904 Reports of the Cambridge Anthropological Expedition to Torres Straits: Sociology, Magic and Religion of the Western Islanders. Vol. 5. Cambridge: Cambridge University Press.

Harris, D.R. and B. Ghaleb 1987 Archaeological and Ecological Investigations on Mabuyag Island. In A.J. Barham and D.R. Harris (eds), Archaeological and Palaeoenvironmental Investigations in Western Torres Strait, Northern Australia. Unpublished report to the Research and Exploration Committee, National Geographic Society.

Harris, D.R., A.J. Barham and B. Ghaleb 1985 Archaeology and Recent Palaeoenvironmental History of Torres Strait, Northern Australia. Unpublished report to the Research and Exploration Committee, National Geographic Society.
Kwan, D., H. Marsh and S. Delean 2006 Factors influencing the sustainability of customary dugong hunting by a remote indigenous community. Environmental Conservation 33(2):164-117.

Lambeck, K. and J. Chappell 2001 Sea level change through the last glacial cycle. Science 292:679-686.

McCormac, F.G., A.G. Hogg, P.G. Blackwell, C.E. Buck, T.F.G. Higham and P.J. Reimer 2004 SHCal04 southern hemisphere calibration, 0-11.0 cal kyr BP. Radiocarbon 46:1087-1092.

McFarlane, S. August 14th 1874 Voyage of the Somerset. Unpublished letter to Reverend Whitehouse. Microfilm from the National Library of Australia, Melbourne.

McNiven, I.J. 2006 Dauan 4 and the emergence of ethnographically-known social arrangements across Torres Strait during the last 600-800 years. Australian Archaeology 62:1-13.

McNiven, I.J. and A. Bedingfield 2008 Past and present marine mammal hunting rates and abundances: Dugong (Dugong dugon) evidence from Dabangay Bone Mound, Torres Strait. Journal of Archaeological Science 35:505-515.

McNiven, I.J., J.A. Crouch, M. Weisler, N. Kemp, L. Clayton Martinez, M. Orr, L. Brady, S. Hocknull and W. Boles 2008 Tigershark Rockshelter (Baidamau Mudh): Seascape and settlement reconfigurations on the sacred islet of Pulu, western Zenadh Kes (Torres Strait). Australian Archaeology 66:15-32.

McNiven, I.J., B. David, Goemulgaw Kod and J. Fitzpatrick 2009 The Great Kod of Pulu: Mutual historical emergence of ceremonial sites and social groups, Torres Strait, northeast Australia. Cambridge Archaeological Journal 19(3):92-108.

McNiven, I.J., W.R. Dickinson, B. David, M. Weisler, M. Carter and U. Zoppi 2006 Mask Cave: Red-slipped pottery and the Australian-Papuan settlement of Torres Strait. Archaeology in Oceania 41(2):49-82.

McNiven, I.J. and R. Feldman 2003 Ritually orchestrated seascapes: Hunting magic and dugong bone mounds in Torres Strait, NE Australia. Cambridge Archaeological Journal 13(2):169-194.

McNiven, I.J. and G. Hitchcock 2004 Torres Strait Islander marine subsistence specialisation and terrestrial animal translocation. In I.J. McNiven and M. Quinnell (eds), Torres Strait Archaeology and Material Culture, pp.105-162. Memoirs of the Queensland Museum, Cultural Heritage Series 3. Brisbane: Queensland Museum.

McNiven, I.J., D. Wright, S. Sutton, M. Weisler, S. Hocknull and J. Stanisic in press Midden formation and marine specialisation at Goemu village, Mabuyag, Torres Strait, before and after European contact. In I.J. McNiven and G. Hitchcock (eds), Goemulgal: Natural and Cultural Histories of the Mabuyag Islands, Zenadh Kes (Torres Strait). Memoirs of the Queensland Museum, Cultural Heritage Series. Brisbane: Queensland Museum.

Moore, D.R. 1979 Islanders and Aborigines at Cape York. Canberra: Australian Institute of Aboriginal Studies.

Moresby, J. 1876 New Guinea and Polynesia: Discoveries and Surveys in New Guinea and the D'Entrecasteaux Islands. London: John Murray.

Murray, A.W. 1873 On board the Lizzie Jardine. Letter dated 9 November. Microfilm from the State Library of Victoria, Melbourne. 
Rowe, C. 2011 A palynological investigation of Holocene vegetation change in Torres Strait, seasonal tropics of northern Australia. Palaeogeography, Palaeoclimatology, Palaeoecology 251:81-103.

Rowland, M.J. 1985 Archaeological investigations on Moa and Naghi Islands, western Torres Strait. Australian Archaeology 21:119-132.

Wright, D. 2011 Mid Holocene maritime economy in the western Torres Strait. Archaeology in Oceania 46(1):23-27.

Wright, D. and G. Jacobsen in press Convergence of ceremonial and secular: The archaeology of Dabangay on Mabuyag in the western Torres Strait. In I.J. McNiven and G. Hitchcock (eds), Goemulgal: Natural and Cultural Histories of the Mabuyag Islands, Zenadh Kes (Torres Strait). Memoirs of the Queensland Museum, Cultural Heritage Series. Brisbane: Queensland Museum.
Wright, D. and G. Jacobsen 2013 Further radiocarbon dates from Dabangay, a mid- to late Holocene settlement site in western Torres Strait. Australian Archaeology 76:79-83. 
